\title{
Efficient Expropriation: Sustainable Fiscal Policy in a Small Open Economy
}

\author{
Mark Aguiar, Manuel Amador, and Gita Gopinath
}

\begin{abstract}
:
We study a small open economy characterized by two empirically important frictions incomplete financial markets and an inability of the government to commit to policy. We characterize the best sustainable fiscal policy and show that it can amplify and prolong shocks to output. In particular, even when the government is completely benevolent, the government's credibility not to expropriate capital varies endogenously with the state of the economy and may be "scarcest" during recessions. This increased threat of expropriation depresses investment, prolonging downturns. It is the incompleteness of financial markets and the lack of commitment that generate investment cycles even in an environment where first-best capital stock is constant.
\end{abstract}

Mark Aguiar is a Senior Economist at the Federal Reserve Bank of Boston. Manuel Amador is an Assistant Professor at Stanford University's Graduate School of Business and a visiting Assistant Professor at Harvard University. Gita Gopinath is an Assistant Professor of Economics at Harvard University and a Faculty Research Fellow at the NBER. Their email addresses are: mark.aguiar@bos.frb.org, amador@stanford.edu, and gopinath@fas.harvard.edu, respectively.

This paper, which may be revised, is available on the web site of the Federal Reserve Bank of Boston at http://www.bos.frb.org/economic/wp/index.htm.

The views expressed in this paper are solely those of the authors and do not reflect official positions of the Federal Reserve Bank of Boston or the Federal Reserve System.

We thank Andy Atkeson, Doireann Fitzgerald, William Fuchs, Pierre-Oliver Gourinchas, Hugo Hopenhayn, Pat Kehoe, Narayana Kocherlakota, Enrique Mendoza, Marcelo Oviedo, Chris Phelan, Ken Rogoff, Paul Romer, Andy Rose, Aleh Tsyvinsky, Carlos Vegh, and Ivan Werning for comments and suggestions. We also thank seminar participants at Berkeley, the Board of Governors of the Federal Reserve System, Cornell, Harvard, Princeton, MIT, the NBER summer institute, SED, the Minneapolis Fed, New York University, Boston University, the New York Fed, Northwestern University, the University of California at Santa Cruz, the University of Texas, the Philadelphia Fed, and the Universidad Torcuato Di Tella for comments.

This version: April 17, 2006 


\section{Introduction}

We study optimal fiscal policy in a small open economy (SOE) characterized by two frictions: incomplete financial markets and an inability of the government to commit to policy. Despite the empirical importance of these two frictions, especially in emerging markets, their combined impact on fiscal policy has not been analyzed in the existing literature. Interestingly, in such an environment, the best policy choice of a benevolent government may amplify and prolong shocks to output. Incomplete markets provide an incentive to use fiscal policy to proxy for missing insurance markets, and the lack of commitment tempts the government to confiscate foreign capital. The government's credibility not to expropriate capital is shown to vary endogenously with the state of the economy and is "scarcest" during recessions. This increased threat of expropriation depresses investment during downturns, generating investment cycles even in an environment in which the first-best capital stock is constant.

In the model, the government implements fiscal policy on behalf of risk-averse domestic agents (or a preferred subset of agents) who lack access to financial markets and do not own capital. Uncertainty is driven by a stochastic endowment process, generating a risk against which the domestic agents cannot insure. Risk-neutral foreigners invest capital in the economy that is immobile for one period and has an opportunity cost given by the world interest rate. The government provides insurance by transferring income between foreign capitalists and domestic agents and is assumed to run a balanced budget. A useful expositional feature of the additive endowment shock is that the marginal product of capital is independent of the shock's realization. That is, the first-best capital stock is acyclical. These assumptions allow us to isolate starkly the role of fiscal policy in generating investment fluctuations.

If the government could commit, the optimal fiscal policy (the Ramsey solution) would not distort capital in this economy (similar to Judd 1985 and Chamley 1986). Without distorting investment, the government can perfectly insure domestic agents across states within a period. It does so by exploiting the fact that capital is sunk for one period. However, given the assumed absence of financial assets, the government cannot transfer resources across periods, and therefore the consumption of domestic agents may still vary over time.

What if the government cannot commit to its promised tax plan? While the sunk nature of capital allows the government to insure domestic agents, it also tempts the government to expropriate all capital ex post. To address this, we follow Chari and Kehoe (1990) and adopt sustainable equilibria as our solution concept.

A main result of the paper proves that there is a range of discount factors for which the 
first-best investment is sustainable for high shocks, but not for low. The intuition stems from the fact that under the Ramsey plan consumption is increasing in the expected endowment: When endowment shocks are persistent, a low endowment today implies low consumption tomorrow. Therefore, the lower the endowment shock today, the greater the government's incentive to deviate tomorrow. In other words, the government's credibility regarding the taxation of next period's capital income is lowest during a bad endowment realization. This is the sense in which credibility is "scarce" during downturns.

Note that this reasoning, as well as the formal proof, does not require strong assumptions regarding the specific shape of the government's objective function (other than strict concavity). Moreover, the result requires minimal characterization of the continuation values.

A common feature of models with incentive compatibility constraints is that these constraints tend to bind in high states. This stems from the nature of insurance - payments are made in high states and benefits are received in low states. Empirically, however, we do not directly observe whether constraints are binding in high or low states. Rather, we observe actions and allocations. Our model is consistent with incentive constraints' binding during good times but distortions appearing during bad times. Specifically, even if the participation constraints bind only in high-endowment states and these states are least likely following a recession (that is, there is persistence), it is during recessions that the capital margin will first be distorted.

We also present results concerning parameterizations in which optimal fiscal policy may lead to sub-optimal investment following every history. We explore the optimal policy analytically and numerically in such cases. We show that there are regions of the parameter space in which investment is larger during low realizations of the endowment shock and provide intuition as to why this may occur. We also explore the sensitivity of our results to alternative asset market structures. We show that our result extends to the case of static insurance markets which allow risk-sharing across states within a period but not across periods. We also show that allowing the government access to a risk-free bond in the Ramsey problem is equivalent to completing the markets. In that environment, the sustainability of the Ramsey fiscal policy is independent of history. This case underscores the importance of incomplete markets in generating the result.

The prediction that the threat of expropriation depresses investment following downturns is reminiscent of emerging-market crises. Governments often allow foreign capital to earn large returns in booms but confiscate capital income during crises. Moreover, as documented by Calvo et al. (2005), investment remains persistently depressed following a crisis. The most recent crisis in Argentina in January 2002 is a dramatic illustration of this phenomenon. 
During the crisis, Argentina repudiated contracts, froze prices on privately owned utilities, and imposed taxes on exports. Measures of expropriation risk as calculated by the Heritage Foundation and Fraser Institute deteriorated sharply. A similar deterioration of property rights is observed in other emerging-market crises. The oscillation between pro-growth policies and populism observed in many developing economies seems to contribute to (rather than stabilize) the volatility of output. Our paper rationalizes such behavior by focusing on two key characteristics that distinguish emerging-market economies: inadequate insurance markets and the inability of governments to commit to future policy promises.

\section{Related Literature}

There is a large literature on the question of optimal taxation by a benevolent social planner. See the survey by Chari and Kehoe (1999) and the references therein. Several papers have studied optimal fiscal policy without commitment. Aside from Chari and Kehoe (1990), in a paper closely related to ours, Benhabib and Velasco (1996) study an open economy where the government lacks commitment and needs to finance productive investment. Their paper differs from ours by considering a deterministic economy. Therefore, there is no scope for fiscal policy to vary with shocks or to provide insurance. Our paper is also related to Phelan and Stacchetti (2001), in which a policy game is analyzed for the case without uncertainty in a closed economy.

In an important paper in the international business cycle literature, Kehoe and Perri (2002) consider a model of risk-sharing across two countries with limited commitment. Differently from Kehoe and Perri (2002), we study a small open economy and emphasize the role of the government in generating amplification. Also related is Thomas and Worrall (1994), which presents a model of a multinational subject to expropriation by a host government that lacks commitment. See also Albuquerque and Hopenhayn (2004).

Tornell and Velasco (1992) and Lane and Tornell (1999) present interesting political economy games in which a "tragedy of the commons" problem arises that may distort investment. However, these papers restrict attention to Markov equilibria, and therefore the issue of state-dependent "reputation" does not arise.

The primary empirical study of emerging markets fiscal policy is Kaminsky, Reinhart and Vegh (2004). They focus on the spending side (see also Talvi and Vegh 2004) and document that emerging markets follow fiscal policies that are more procyclical than those in developed economies. While the quarterly cyclicality of government expenditures is an important issue, our focus is on the expropriation of foreign capital during crises. 
The paper is organized as follows. In Section 1 we present the model with endowment shocks and describe the full-commitment solution. Section 2 presents the limitedcommitment results. Section 3 extends the model to environments with richer asset markets, and Section 4 concludes.

\section{Model}

Time is discrete and runs to infinity. The economy is composed of a government and two types of agents: domestic agents and foreign capitalists. Domestic agents (or "workers") are risk averse and supply inelastically $l$ units of labor every period for a wage $w$. In addition, they receive an endowment shock $z$ every period that has the following properties:

Assumption 1. $z \in Z$ follows a Markov process and the finite set $Z$ has a highest element $\bar{z}<\infty$ and a lowest element $\underline{z}>0$.

Let $z^{t}=\left\{z_{0}, z_{1}, \ldots z_{t}\right\}$ be a history of endowment shocks up to time $t$. Denote by $q\left(z^{t}\right)$ the probability that $z^{t}$ occurs.

The expected lifetime utility of workers is given by

$$
\sum_{t=0}^{\infty} \sum_{z^{t}} \beta^{t} q\left(z^{t}\right) u\left(c\left(z^{t}\right)\right)
$$

where $c\left(z^{t}\right)$ is their consumption in history $z^{t}$ and $u$ is a standard utility function with $u^{\prime}>0, u^{\prime \prime}<0$, and $\beta \in(0,1)$ is the discount factor.

Assumption 2 (Segmented Capital Markets). Workers do not have access to financial markets. Their consumption is given by

$$
c\left(z^{t}\right)=z_{t}+w\left(z^{t}\right) l+T\left(z^{t}\right)
$$

where $T\left(z^{t}\right)$ are transfers received from the government at history $z^{t}$ and $w\left(z^{t}\right)$ is the competitive wage at history $z^{t}$.

There exists a continuum of risk-neutral foreign capitalists who supply capital, but no labor. The foreign capitalists own competitive domestic firms that produce by hiring domestic labor and using foreign capital. The production function $F$ is of the standard neoclassical form: 


$$
y=F(k, l),
$$

where $F$ is constant returns to scale with $F_{k}>0$ and $F_{k k}<0$.

The capitalists have access to financial markets. We assume a small open economy where the capitalists face the exogenous world interest rate of $r^{*}$. We assume that capital is installed before the endowment shock and tax rate are realized and cannot be moved until the end of the period. For simplicity, we assume the depreciation rate is 0 . Capital profits are denoted $\pi\left(z^{t}\right)$, where

$$
\pi\left(z^{t}\right)=F\left(k\left(z^{t-1}\right), l\right)-w\left(z^{t}\right) l .
$$

We make the following assumption about the government's objective function:

Assumption 3 (Redistributive Government). The government's objective function is to maximize the lifetime utility of the workers.

We model the government as benevolent towards domestic workers. Alternatively, we could assume that the government maximizes the utility of a subset of agents, such as political insiders or public employees. The analysis will make clear that our results extend to these alternative objective functions as long as the favored agents are risk averse and lack access to capital markets.

The government taxes capital profits at a linear rate $\tau\left(z^{t}\right)$ and transfers the proceeds to the workers $T\left(z^{t}\right)$. We assume the government does not have access to international financial markets:

Assumption 4 (Balanced Budget). The government runs a balanced budget at every state:

$$
\tau\left(z^{t}\right) \pi\left(z^{t}\right)=T\left(z^{t}\right) .
$$

This is an important assumption. Several other studies have exploited a balanced-budget assumption, including Benhabib and Velasco (1996), Krusell and Rios-Rull (1999), and Phelan and Stacchetti (2001). We discuss relaxing this constraint in Section 3.2.

Taking as given a tax rate plan $\tau\left(z^{t}\right)$, firms maximize after-tax profits discounted at the world interest rate,

$$
E_{0} \sum_{t}\left(\frac{1}{1+r^{*}}\right)^{t}\left(1-\tau\left(z^{t}\right)\right) \pi\left(z^{t}\right) .
$$


Profit maximization implies the following two first-order conditions:

$$
F_{l}\left(k\left(z^{t-1}\right), l\right)=w\left(z^{t}\right),
$$

and

$$
r^{*}=E\left[\left(1-\tau\left(z^{t}\right)\right) \mid z^{t-1}\right] F_{k}\left(k\left(z^{t-1}\right), l\right),
$$

where $E\left[. \mid z^{t-1}\right]$ indicates expectation conditional on history $z^{t-1}$, and $F_{i}$ denotes the partial derivative of $F$ with respect to $i=k, l$.

According to equation (2), the expected return to capitalists from investing in the domestic economy should equal the world interest rate $r^{*}$. Given the additive nature of the endowment shock, optimal capital is a constant in a world without taxes.

\subsection{Optimal Taxation under Commitment}

In this subsection, we characterize the optimal fiscal policy under commitment. We show that tax policy is not distortionary and that investment will be a constant at the first-best level.

Suppose that the government can commit at time 0 to a tax policy $\tau\left(z^{t}\right)$ for every possible history of shocks $z^{t}$. This (Ramsey) plan is announced before the initial capital stock is invested. The government chooses $c\left(z^{t}\right), k\left(z^{t}\right)$, and $\tau\left(z^{t}\right)$ to maximize

$$
\sum_{t=0}^{\infty} \sum_{z^{t}} \beta^{t} q\left(z^{t}\right) u\left(c\left(z^{t}\right)\right)
$$

subject to

$$
\begin{gathered}
c\left(z^{t}\right)=z_{t}+w\left(z^{t}\right) l+T\left(z^{t}\right), \\
\tau\left(z^{t}\right)\left(F\left(k\left(z^{t-1}\right), l\right)-w\left(z^{t}\right) l\right)=T\left(z^{t}\right), \\
F_{l}\left(k\left(z^{t-1}\right), l\right)=w\left(z^{t}\right),
\end{gathered}
$$

and

$$
r^{*}=E\left[\left(1-\tau\left(z^{t}\right)\right) \mid z^{t-1}\right] F_{k}\left(k\left(z^{t-1}\right), l\right) .
$$

By combining the worker and government budget constraints with the optimal labor 
condition of the firms (equation 5), we obtain

$$
c\left(z^{t}\right)=z_{t}+F\left(k\left(z^{t-1}\right), l\right)-\left(1-\tau\left(z^{t}\right)\right) F_{k}\left(k\left(z^{t-1}\right), l\right) k\left(z^{t-1}\right) .
$$

We have used the constant-returns-to-scale assumption and Euler's theorem, $F(k, l)=F_{k} k+$ $F_{l} l$. Taking expectations of equation (7) and substituting in equation (2), we obtain a single aggregate constraint in expectation,

$$
E\left[z_{t} \mid z^{t-1}\right]+F\left(k\left(z^{t-1}\right), l\right)-E\left[c\left(z^{t}\right) \mid z^{t-1}\right]-r^{*} k\left(z^{t-1}\right)=0 .
$$

This constraint states that the sum of the expected endowment and produced output should equal the sum of expected consumption and payments to capitalists. The following lemma uses equation (8) to simplify the constraint set:

Lemma 1. For any $c\left(z^{t}\right)$ and $k\left(z^{t-1}\right)$ that satisfy (8), there exists a function $\tau\left(z^{t}\right)$ such that (7) and (6) are satisfied.

Proof. For a given $c\left(z^{t}\right)$ and $k\left(z^{t-1}\right)$, define $\tau\left(z^{t}\right)$ as the solution to (7). The fact that (6) holds follows directly from (8).

The previous result exploits the fact that capitalists care only about the expected return to capital. Given an expected ex post profit, the government can use taxes to transfer resources to workers across states.

The problem of the government under commitment is then to maximize

$$
\sum_{t=0}^{\infty} \sum_{z^{t}} \beta^{t} q\left(z^{t}\right) u\left(c\left(z^{t}\right)\right),
$$

subject to $(8)$.

Proposition 1. Under commitment, the optimal fiscal policy:

(i) Provides full intra-period insurance to the workers:

$$
c\left(\left\{z_{t}, z^{t-1}\right\}\right)=c\left(\left\{z_{t}^{\prime}, z^{t-1}\right\}\right) \text { for all }\left(z_{t}, z_{t}^{\prime}\right) \in Z_{t} \times Z_{t} \text { and } z^{t-1} \in Z^{t-1} \text {, and }
$$

(ii) At the begining of every period, the expected capital tax payments are zero:

$$
E\left[\tau\left(z^{t}\right) \mid z^{t-1}\right]=0
$$


Proof. The Lagrangian of the problem is

$$
\sum_{t=0}^{\infty} \beta^{t}\left[\sum_{z^{t}} q\left(z^{t}\right) u\left(c\left(z^{t}\right)\right)+\sum_{z^{t-1}} q\left(z^{t-1}\right) \gamma\left(z^{t-1}\right)\left\{\begin{array}{c}
E\left[z_{t} \mid z^{t-1}\right]+F\left(k\left(z^{t-1}\right), l\right) \\
-E\left[c\left(z^{t}\right) \mid z^{t-1}\right]-\left(r^{*}\right) k\left(z^{t-1}\right)
\end{array}\right\}\right]
$$

where $z^{t-1}$ evaluated at $t=0$ refers to the initial information set. Notice that if $\gamma\left(z^{t-1}\right)$ is non-negative, the Lagrangian is concave on $c, k$. The first-order conditions for the maximization of the Lagrangian are

$$
\begin{aligned}
u^{\prime}\left(c\left(z^{t}\right)\right) & =\gamma\left(z^{t-1}\right), \text { and } \\
F_{k}\left(k\left(z^{t-1}\right), l\right) & =r^{*},
\end{aligned}
$$

where the first condition implies that $c\left(\left\{z_{t}, z^{t-1}\right\}\right)=c\left(\left\{z_{t}^{\prime}, z^{t-1}\right\}\right)$ for all $\left(z_{t}, z_{t}^{\prime}\right) \in Z_{t} \times Z_{t}$ and the second condition implies that $E\left[\tau\left(z^{t}\right) \mid z^{t-1}\right]=0$.

Proposition 1 shows that the government can insure all the intra-period risk the workers are facing without distorting investment: $F_{k}\left(k\left(z^{t-1}\right), l\right)=r^{*}$. In this model, it is efficient to set expected tax payments on capital equal to zero, a result well known in the Ramsey taxation literature (Judd (1985), Chamley (1986), and the stochastic version in Zhu (1992)). Chari, Christiano, and Kehoe (1994) obtain a similar result in a business cycle model. The small open economy assumption implies that capital is infinitely elastic ex ante and therefore that the zero-taxation of capital is optimal at all dates and not just asymptotically. See Chari and Kehoe (1999) for a related discussion.

A quick corollary follows,

Corollary 1. Under commitment, (i) realized capital taxes are countercyclical:

$$
\tau\left(z_{t}, z^{t-1}\right)>\tau\left(z_{t}^{\prime}, z^{t-1}\right) \quad \text { for } z_{t}<z_{t}^{\prime}
$$

(ii) If $E\left[z_{t} \mid z^{t-1}\right]$ is increasing in $z^{t-1}$, then $\tau\left(z_{t}, z^{t-1}\right)$ is increasing in $z^{t-1}$.

Proof. From (7), it is possible to solve for the tax rate:

$$
\tau\left(z_{t}, z^{t-1}\right)=\frac{E\left[z_{t} \mid z^{t-1}\right]-z_{t}}{r^{*} k}
$$

Since $k$ is independent of $z_{t}$ and $z_{t-1}$, the results follow.

Note that the Ramsey allocation is independent of the discount factor $\beta$. 
The government taxes capitalists and transfers to workers in low-endowment states while transferring from workers to capitalists in high-endowment states. It does so in such a way that the expected tax burden on capital is zero and the workers are fully insured across states within a period. The government exploits the fact that capital is ex post inelastic to transfer capital income across states so that worker consumption is equalized. The ex ante elasticity of capital provides the necessary incentive to keep average tax payments at zero. The results in this section tell us that a government with commitment would not amplify shocks through its tax policy.

\section{Optimal Taxation with Limited Commitment}

We now turn to the important question of the best policy in the absence of commitment. Once the investment decision by the capitalists has been made, the government would like to tax capital as much as possible and redistribute the proceeds to the workers. Thus, the optimal tax policy under commitment may not be dynamically consistent. As is standard in the literature, we model the economy as a game between the capitalists and the government and use sustainability (Chari and Kehoe 1990) as our solution concept. In this section, we characterize the best sustainable equilibria of the game.

We assume the following:

Assumption 5 (A Maximum Tax Rate). At any state $z$, the tax rate on capital cannot be higher than $\bar{\tau}>0$.

Throughout the analysis, we assume that $\bar{\tau}$ is greater than the maximal tax rate under the Ramsey plan (the Ramsey plan is feasible).

Let $h_{t-1}$ be the history of tax policies and endowment shocks up to the beginning of period $t: h_{t-1}=\left\{\left(\tau_{s}, z_{s}\right) \mid s=0, \ldots, t-1\right\}$. As shown by Chari and Kehoe (1990), we do not need to include the capitalists' previous investment decisions in the definition of the history. A government's policy rule at time $t$ is a function $\tau_{t}\left(h_{t-1}, z_{t}\right)$ that maps previous histories and the current shock into a tax rate less than or equal to $\bar{\tau}$. A capitalist's investment rule at time $t$ is a function $k\left(h_{t-1}\right)$ that maps previous histories into a capital level. A government policy plan is a sequence of policy rules $\sigma=\left\{\tau_{0}, \tau_{1}, \ldots\right\}$. A capitalist's investment plan $\kappa=\left\{k_{0}, k_{1}, \ldots\right\}$ is a sequence of investment rules.

Definition 1. A sustainable equilibrium is a pair $(\sigma, \kappa)$ such that: 
(i) Given a policy plan $\sigma$ and any history $h_{t-1}$, the associated investment rule under $\kappa$, $k_{t}\left(h_{t-1}\right)$, is the value of $k$ that solves

$$
r^{*}=E\left[\left(1-\tau\left(h_{t-1}, z_{t}\right)\right) F_{k}(k, l) \mid z^{t-1}\right] .
$$

(ii) Given $\kappa$, for any history $\left(h_{t-1}, z_{t}\right)$, the continuation of the policy plan $\sigma$ maximizes the expected lifetime utility of the workers from $t$ onwards subject to the budget constraint (7).

\subsection{The Worst Equilibrium}

To characterize the best sustainable equilibrium, we first study the worst equilibrium. In this model, the worst equilibrium is easy to characterize.

Define $\sigma_{W}$ as a tax policy that sets $\tau$ equal to $\bar{\tau}$ at every history. Define $\kappa_{W}$ as the investment plan that sets capital to $k_{W}$ at each history, where $k_{W}$ solves $r^{*}=(1-\bar{\tau}) F_{k}\left(k_{W}, l\right)$. Then the following holds:

Proposition 2 (Worst Equilibrium). The pair $\left(\sigma_{W}, \kappa_{W}\right)$ is a sustainable equilibrium. In particular, of all sustainable equilibria, after any history $h_{t-1},\left(\sigma_{W}, \kappa_{W}\right)$ generates the lowest payoff to the government.

Proof. To show that $\left(\sigma_{W}, \kappa_{W}\right)$ is an equilibrium, note that if the capitalists believe that the government will tax at the maximum rate in the next period, then investing $k_{W}$ is a best response. Note that if after any history $\left(h_{t-1}, z_{t}\right)$ the government believes that the capitalists will follow the investment plan $\kappa_{W}$ in the future, then it is optimal for the government to tax at the maximum rate today.

To show that this equilibrium is a lower bound for the the government's payoff, note first that in any equilibrium at any possible history, we know that $k\left(z^{t}\right) \geq k_{W}$. This is because taxes are restricted to be at most $\bar{\tau}$ and the expected after-tax marginal product of capital would be greater than $r^{*}$ for any $k<k_{W}$. Given that $c(k)=z+F(k, l)-(1-\bar{\tau}) F_{k}(k, l)$ is increasing in $k$, taxing at $\bar{\tau}$ generates consumption at least as high as $c\left(k_{W}\right)$. Starting from any $k$, the government, by taxing at $\bar{\tau}$, can thus guarantee a payoff at least as high as that of $\left(\sigma_{W}, \kappa_{W}\right)$.

Let $W\left(h_{t-1}\right)$ be the payoff to the government at the beginning of period $t$ after a history $h_{t-1}$ under the equilibrium $\left(\sigma_{W}, \kappa_{W}\right)$. Given the Markovian nature of the endowment shocks 
and the fact that tax rates are always $\bar{\tau}$ in any history in this equilibrium, we can redefine $W$ as a function of the current realization $W\left(z_{t-1}\right)$. We can use this function $W$ to recursively generate the sustainable equilibria. We turn to the characterization of these equilibria in the next subsection.

\subsection{The Best Sustainable Equilibrium}

We can characterize the set of sustainable equilibrium payoffs by using reversion to the worst equilibrium as the punishment to government deviations (see Chari and Kehoe 1990). We are interested in the equilibrium that provides the government with its highest payoff. We refer to this as the best sustainable equilibrium. We denote strategies in this equilibrium as $\left(\sigma^{*}, \kappa^{*}\right)$.

To set notation, we define the value function of the government under the best equilibrium as follows. Let $V\left(h_{t-1}\right)$ denote the government's expected payoff after history $h_{t-1}$ at the beginning of period $t$ before shocks and investment are realized. This value function holds under any history in which the government has not deviated from strategy $\sigma^{*}$. It is possible to show that best equilibrium payoff can be attained through stationary strategies. To see this, note that the punishment $W$ is stationary, as are the budget constraint (8) and the government's objective function. Therefore, for any sustainable equilibrium with timedependent strategies, there exists a sustainable equilibrium with stationary strategies that achieves at least as high a payoff. Given this and the Markov nature of $z$, we can redefine $V$ as a function of the current shock, $V\left(z_{t-1}\right)$. Note that the small open economy assumption makes capital a choice variable each period. That is, the economy freely adjusts capital at the end of each period through international capital flows. The best equilibrium payoff $V$ can be shown to solve the following Bellman equation:

$$
V\left(z_{t-1}\right)=\max _{k, c(\cdot)} E\left[u\left(c\left(z_{t}\right)\right)+\beta V\left(z_{t}\right) \mid z_{t-1}\right]
$$

subject to

$$
E\left[z_{t} \mid z_{t-1}\right]+F(k, l)-E\left[c\left(z_{t}\right) \mid z_{t-1}\right]-r^{*} k=0
$$

and

$$
u\left(c\left(z_{t}\right)\right)+\beta V\left(z_{t}\right) \geq u\left(\bar{c}\left(z_{t}, k\right)\right)+\beta W\left(z_{t}\right), \forall z_{t} \in Z
$$

for

$$
\bar{c}\left(z_{t}, k\right)=z_{t}+F(k, l)-(1-\bar{\tau}) F_{k} k
$$


where $W$ is the continuation value of the government in the worst equilibrium.

Equation (11) is the budget constraint of the government, and the inequalities (12) are the participation constraints. Note that the presence of concave functions of choice variables on both sides of constraint (12) implies that the constraint set is not convex. However, since the Bellman operator in (10) is monotone, a numerical solution can be found by iterating down using the full commitment payoff as the initial guess for $V$. Subsection 2.5 describes the results of a numerical analysis.

As a first step in characterizing the best equilibrium, we prove a Folk theorem.

Proposition 3 (A Folk theorem). There exists a $\beta^{*} \in(0,1)$ such that for all $\beta \geq \beta^{*}$ the Ramsey solution is sustainable, and it is not sustainable for $\beta \in\left[0, \beta^{*}\right)$.

Proof. Note that the Ramsey and the worst equilibrium's allocations are independent of the value of $\beta$. Let $c^{R}\left(z_{t-1}\right)$ denote consumption at time $t$ under the Ramsey plan, conditional on $z_{t-1}$. Recall that consumption under the Ramsey plan at time $t$ is independent of $z_{t}$. Let $c^{W}\left(z_{t}\right)$ denote the consumption allocations under the worst equilibrium, given a current endowment $z_{t}$. For a given $\beta$, define $\Omega\left(z_{t-1}, \beta\right)$ as $\beta$ times the difference in the government's payoff between the Ramsey allocation and the worst equilibrium:

$$
\Omega\left(z_{t_{0}}, \beta\right) \equiv \sum_{t=t_{0}}^{\infty} \beta^{t+1-t_{0}} \sum_{z^{t}} q\left(z^{t} \mid z_{t_{0}}\right)\left[u\left(c^{R}\left(z_{t}\right)\right)-\sum_{z_{t+1}} q\left(z_{t+1} \mid z^{t}\right) u\left(c^{W}\left(z_{t+1}\right)\right)\right] .
$$

The terms in square brackets on the right-hand side of (14) represent the difference in utility of the Ramsey plan relative to that under the worst equilibrium. This difference is strictly positive. The optimality of the Ramsey plan implies that the difference is nonnegative. That it is strictly positive follows from the fact that $k^{*}>k^{W}$, given that $\bar{\tau}>0$. This implies that $\Omega$ is strictly increasing in $\beta$, is equal to zero when $\beta=0$, and approaches infinity as $\beta$ approaches one.

We can write the participation constraints at the Ramsey allocation as

$$
u\left(c^{R}\left(z_{t-1}\right)\right)-u\left(\bar{c}\left(z_{t}, k^{*}\right)\right) \geq-\Omega\left(z_{t}, \beta\right)
$$

As the right-hand side of (15) is increasing in $\beta$, and the left-hand side does not vary with $\beta$, if this constraint is satisfied at $\beta^{0}$, then it is satisfied at any $\beta>\beta^{0}$. When $\beta=0$, the right-hand side of (15) is zero and the constraint will not hold for some $z$. When $\beta \rightarrow 1$, the right-hand side of (15) approaches minus infinity, implying there is a $\beta^{*}<1$ for which all 
the participation constraints are satisfied at the Ramsey allocation for $\beta \geq \beta^{*}$, and at least one constraint is violated at the Ramsey allocation for $\beta<\beta^{*}$.

When the government is sufficiently patient, the Ramsey solution is sustainable. As before, this will imply a fiscal policy that does not distort capital. The interesting question is, however, what happens when the government is not sufficiently patient to sustain the Ramsey solution, nor sufficiently impatient that the worst equilibrium is the unique sustainable equilibrium.

The following lemma is the first step towards an answer. Let $k(z)$ and $c\left(z^{\prime} \mid z\right)$ be the respective policy rules that solve the Bellman equation (10) at state $z$.

Lemma 2. In a best equilibrium,

(i) For all states $z, F_{k}(k(z), l) \geq r^{*}$;

(ii) For any state $z_{t-1}$, if the participation constraints (12) are slack for a subset $Z_{o} \subset Z$, then $c\left(z \mid z_{t-1}\right)=c\left(z^{\prime} \mid z_{t-1}\right)$ for all $\left(z, z^{\prime}\right) \in Z_{o} \times Z_{o}$;

(iii) If for some $\left(z, z^{\prime}\right) \in Z \times Z$ we have that $c\left(z \mid z_{t-1}\right) \neq c\left(z^{\prime} \mid z_{t-1}\right)$, then $F_{k}\left(k\left(z_{t-1}\right), l\right)>r^{*}$.

Proof. A necessary condition for an optimum is that there exist multipliers $\lambda(z) \geq 0$ and $\gamma$ such that

$$
\gamma\left\{F_{k}(k, l)-r^{*}\right\}-\sum_{z_{t}} \lambda\left(z_{t}\right) u^{\prime}\left(\bar{c}\left(z_{t}, k\right)\right) \bar{c}_{k}\left(z_{t}, k\right)=0
$$

Another necessary condition for an optimum is that

$$
\begin{gathered}
\left(q\left(z_{t} \mid z_{t-1}\right)+\lambda\left(z_{t}\right)\right) u^{\prime}\left(c\left(z_{t}\right)\right)-\gamma q\left(z_{t} \mid z_{t-1}\right)=0 \\
\Leftrightarrow\left(1+\lambda\left(z_{t}\right) / q\left(z_{t} \mid z_{t-1}\right)\right) u^{\prime}\left(c\left(z_{t}\right)\right)=\gamma .
\end{gathered}
$$

This implies that $\gamma \geq 0$. Using the definition of $\bar{c}_{k}$ (equation 13 ), we have that $\bar{c}_{k}>0$. Equation (16) then implies $(i)$.

For part $(i i)$, note for all $z_{0} \in Z_{0}, \lambda\left(z_{o}\right)=0$ and from $(17), u^{\prime}\left(c\left(z_{o}\right)\right)=\gamma$. Strict concavity of $u$ implies the result.

For part (iii), note that if $c\left(z_{t}\right)$ is not constant for all $z_{t} \in Z$ at an optimum (by the hypothesis of part $($ iii $)$ ) then strict concavity implies that $\lambda\left(z_{t}\right)>0$ for some $z_{t}$. Given that $\lambda(z) \geq 0$, with strict inequality for at least one $z \in Z$, together with the fact that $u^{\prime}$ and $\bar{c}_{k}$ are strictly positive, equation (16) implies (iii) . 
The first part of the lemma states that capital never exceeds the first-best level. Benhabib and Rustichini (1997) show that in a deterministic closed economy model of capital taxation without commitment, there are situations where capital is subsidized in the long run, pushing capital above the first-best level. In our case, with an open economy, such a situation never arises.

The second part states that the planner will always implement insurance across states to the extent possible. If two states have unequal consumption and slack constraints, it is a strict improvement (due to risk aversion) to narrow the gap in consumption.

The final part of the lemma states that if the government fails to achieve perfect insurance, it will also distort capital. To see the intuition for this result, suppose that capital was at its first-best level but consumption was not equalized across states. The government could distort capital down slightly to relax the participation constraints. This has a second-order effect on total resources in the neighborhood of the first-best capital stock. However, the relaxation of the participation constraints allows the government to improve insurance. Starting from an allocation without perfect insurance, this generates a first-order improvement in welfare.

The lemma indicates that outside the Ramsey allocation, capital will be distorted down and full insurance will be unattainable. We now turn to the question, in which states will the Ramsey allocation fail to be sustainable.

\subsection{Persistent Shocks and Amplification}

In this subsection we prove our main result that investment is distorted "first" following low shocks.

A careful look at the government's program (10) reveals that what links one period to the next is the conditional distribution over the next period's endowment. In particular, as seen from the budget constraint (8), the current shock determines the expected resources to be divided next period between domestic and foreign agents.

In a world in which the current endowment shocks are signals about the distribution of endowment shocks tomorrow, the promises of future taxation will be functions of the current state. How do these promises change with the state of the economy? Is it harder for a government to make promises of not taxing capital following good times or bad?

We begin by defining "persistence" and "full support" in our framework: 
Definition 2 (Persistent Shocks and Full Support). The endowment shocks are persistent if $E\left(z^{\prime} \mid z\right)$ is strictly increasing in $z$. The process $z$ has full support if for every pair $\left(z^{\prime}, z\right) \in Z \times Z, q\left(z^{\prime} \mid z\right)>0$.

Our main proposition is as follows:

Proposition 4 (Distortion in Bad States). Suppose that the endowment process is persistent and has full support. In a best sustainable equilibrium, if $k(z)=k^{*}$ for some $z \in Z$, then $k\left(z^{\prime}\right)=k^{*}$ for all $z^{\prime}>z$.

Proof. Consumption under full commitment can be written as:

$$
c^{R}(z)=E(\hat{z} \mid z)+F\left(k^{*}, l\right)-r k^{*},
$$

where $k^{*}$ is such that $F_{k}\left(k^{*}, l\right)=r$. As stated before, consumption under commitment is independent of the current realization of the endowment shock, $\hat{z}$ (perfect intra-period insurance). The fact that $k(z)=k^{*}$ implies that the first-best capital level is attained following a $z$ shock. We know then from lemma (2) and the full support assumption that for any $\hat{z}$ following $z, c(\hat{z} \mid z)=c^{R}(z)$. This implies that all the participation constraints following $z$ are satisfied:

$$
u\left(c^{R}(z)\right) \geq u\left(\bar{c}\left(\hat{z}, k^{*}\right)\right)+\beta(V(\hat{z})-W(\hat{z})), \forall \hat{z} \in Z
$$

The full support assumption guarantees that following $z$, a participation constraint exists and is satisfied for every element of $Z$. Note that all terms on the right-hand side of (19) the continuation values as well as the deviation consumption - depend only on $\hat{z}$ and not on $z$. Note as well that $c^{R}(z)$ depends on $z$ only through $E(\hat{z} \mid z)$. Therefore, the persistence assumption implies that $c^{R}(z)$ is increasing in $z$. Therefore, for $z^{\prime}>z, c^{R}\left(z^{\prime}\right)>c^{R}(z)$. It follows from (19) that the participation constraints are satisfied at the Ramsey allocations for all $z^{\prime}>z$.

We postpone discussion of the intuition of this result until we prove one more proposition. The above proposition concerns the case in which the Ramsey allocation is sustainable following certain states but is not sustainable following others. The theorem then characterizes the nature of these two sets. This leaves open the question of whether such a situation ever arises. That is, we have not ruled out the possibility that either the Ramsey allocation is sustainable for all states or it is sustainable for no state. Proposition 5 proves that there always exist discount rates for which the main proposition is relevant. 
Define $V(z \mid \beta)$, and $W(z \mid \beta)$ as the best equilibrium and worst equilibrium value functions (as before), but in this notation we make explicit that the payoffs are functions of $\beta$. As a first step toward Proposition 5, we note that at the $\beta^{*}$ of the Folk theorem,

Lemma 3 (Continuity). For all $z \in Z$, the value function, $V(z \mid \beta)$, is continuous at $\beta^{*}$.

Proof. See Appendix B.

We now show that there exists a range of $\beta \mathrm{s}$ for which our main proposition is relevant.

Proposition 5. Suppose that the endowment process is persistent and has full support. Then, there exists $\beta_{0}$ such that for all $\beta \in\left(\beta_{0}, \beta^{*}\right)$, we can define an associated $z_{\beta}<\bar{z}$ with $k(z)<k^{*}, \forall z \leq z_{\beta}$ and $k(z)=k^{*}, \forall z>z_{\beta}$.

Proof. Define $I C^{R}\left(z^{\prime}, z \mid \beta\right)$ :

$$
I C^{R}\left(z^{\prime}, z \mid \beta\right) \equiv u\left(c^{R}(z)\right)+\beta V\left(z^{\prime} \mid \beta\right)-u\left(\bar{c}\left(z^{\prime}, k^{*}\right)\right)-\beta W\left(z^{\prime} \mid \beta\right) .
$$

By definition (and full support) note that at $\beta^{*}, I C^{R}\left(z^{\prime}, \underline{z} \mid \beta^{*}\right)=0$ for some $z^{\prime} \in Z$. Note as well that persistence implies $c^{R}(\bar{z})>c^{R}(\underline{z})$. Therefore, $I C^{R}\left(z^{\prime}, \bar{z} \mid \beta^{*}\right)>I C^{R}\left(z^{\prime}, \underline{z} \mid \beta^{*}\right) \geq$ $0, \forall z^{\prime} \in Z$. By continuity in $\beta$ of $V(z \mid \beta)$ at $\beta^{*}$ (from the previous lemma), we can find a $\beta_{0}$ such that for all $\beta \in\left(\beta_{0}, \beta^{*}\right), I C^{R}\left(z^{\prime}, \bar{z} \mid \beta\right) \geq 0, \forall z^{\prime} \in Z$. Therefore, for each $\beta \in\left(\beta_{0}, \beta^{*}\right)$, there exists at least one element of $Z$ such that $k(z)=k^{*}$. By the Folk theorem and part (iii) of Lemma 2 , there is at least one $z \in Z$ such that $k(z)<k^{*}$. The additional properties of $z_{\beta}$ follow from Proposition 4 .

The intuition behind Proposition 4 is as follows. If shocks have persistence, consumption in the Ramsey plan will be higher following a higher endowment shock. The deviation consumption and the continuation values depend only on the realized shock next period. Thus, the gains to deviation will be greater in any state following a recession. Consequently, the government may not be able to commit to the Ramsey taxes (which are zero on average), following a low shock. Therefore, capitalists expect average taxes to be positive, leading to sub-optimal investment. The proposition implies that the inability to commit may result in an economy in which capital fluctuates, despite a constant optimal capital level.

Proposition 5 tells us more: Given any strictly concave utility function, and any shock process that satisfies persistence and full support, there always exists a non-empty region of government impatience (as measured by $\beta$ ) such that, in the best sustainable equilibrium, investment is distorted for low realizations of the endowment and undistorted for high. 
Proposition 4 presents a general result. It does not require any particular shape of the utility function other than concavity. In particular, we do not need a full characterization of the continuation values $V$ and $W$. However, this generality relies on fairly strong assumptions regarding asset markets, in particular the absence of government debt. We discuss this further in Section 3.2.

A common feature of models of insurance with limited commitment is that the participation constraints tend to bind when the endowment is high. This results from the fact that insurance calls for payments during booms and inflows during downturns. However, in precisely an environment that emphasizes insurance, we show that distortions of investment can occur during recessions despite undistorted investment during booms. In fact, even if the participation constraints bind only in high-endowment states and these states are least likely following a recession (that is, there is persistence), it is during recessions that the capital margin will first be distorted.

The proposition relies on the fact that the utility function is strictly concave. If utility is linear, the government is "free" to allocate consumption across states to minimize the temptation to tax capital ex-post and maximize expected output. We can show that in this case, investment is a (perhaps sub-optimal) constant, independent of the history of shocks. There is no propagation of the shocks through fiscal policy. It is, then, the desire to provide insurance to risk-averse agents (in the absence of commitment) that motivates the government to distort investment downward during recessions.

Note also that if the endowment follows an i.i.d. process, distortions to investment are independent of the current shock. Under an i.i.d. process, the conditional distribution of tomorrow's endowment is independent of today's realization. This implies that $V$ and $W$ are constants, as is consumption under the Ramsey plan. Therefore, gains from deviation are independent of previous shocks. Investment may be distorted, but will be constant.

The benchmark model considers the case of an additive "endowment" shock. Under fairly standard restrictions on either the production function or the utility function, the result extends to a multiplicative "productivity" shock. The main difference between additive and multiplicative shocks is that first-best capital is not constant in the latter case. This implies that the gains from expropriation depend on the expected shock, both through the promised consumption (as before) and through the (now changing) level of capital. This case is explored in detail in Appendix A.

Finally, we stress that the result does not depend crucially on the benevolence of the government toward all domestic agents. As the derivation makes clear, the important ele- 
ment is that the government is maximizing a concave utility function using linear taxes on capital. The analysis holds if "consumption" in the government's objective function represents consumption by a subset of domestic agents, such as government employees or political insiders. The key assumption is that the favored constituents are risk averse and lack access to financial markets.

\subsection{Going Beyond the Main Proposition}

In this subsection we explore to what extent the intuition that we obtained in a neighborhood of the first-best carries over to the rest of the parameter space. Proposition 4 characterizes the optimum for parameters in a neighborhood of the first best. Our result there was quite general: As long as the shocks are persistent, capital is distorted first in states where the endowment is low. However, it is also of interest to know what would happen when we move away from the first best. To streamline the analysis, we assume in this subsection that $\bar{\tau}=1$.

For expositional purposes, we decompose the response of the optimal capital to a change in $z$ into two separate effects. The "income" effect captures the response of capital to an increase in the expected endowment, holding constant the probabilities. The "substitution" effect captures the response to a change in probabilities, holding constant the expected endowment. This language is meant to be suggestive and does not correspond precisely to the standard usage in demand theory.

More precisely, consider an expected endowment $\mu$ and probabilities $P=[p(\underline{z}), \ldots, p(\bar{z})]$. Given a value function $V(z)$, define

$$
\tilde{V}(P, \mu ; V)=\max _{k, c\left(z^{\prime}\right)} \sum_{z^{\prime}} p\left(z^{\prime}\right)\left\{u\left(c\left(z^{\prime}\right)\right)+\beta V\left(z^{\prime}\right)\right\}
$$

subject to

$$
\begin{aligned}
\sum_{z^{\prime}} p\left(z^{\prime}\right) c\left(z^{\prime}\right)-F(k)+r k & \leq \mu \\
u\left(\bar{c}\left(z^{\prime}, k\right)\right)-u\left(c\left(z^{\prime}\right)\right)+\beta\left(W\left(z^{\prime}\right)-V\left(z^{\prime}\right)\right) & \leq 0, \forall z^{\prime} \in Z .
\end{aligned}
$$

The solution to this relaxed problem yields a policy function for $k, \tilde{k}(P, \mu ; V)$. To relate the relaxed problem to the original problem of interest, note that the optimal $k(z)$ coincides with $\tilde{k}$ at an endowment $z$ when $p\left(z^{\prime}\right)=q\left(z^{\prime} \mid z\right), \forall z^{\prime} \in Z$, and $\mu=\sum_{z^{\prime}} q\left(z^{\prime} \mid z\right) z^{\prime}$.

We now consider the response of $\tilde{k}$ to an increase in $\mu$ as well as a change in $P$. In both 
experiments, we take the continuation value function $V\left(z^{\prime}\right)$ as given. This reflects the fact that the original problem's state variable $z$ influences ex ante payoffs through its effect on the probability measure over next period's endowments. We therefore consider the impact on investment of alternative values of $z$ by separately exploring the impact of changes to $\mu$ and $P$, holding all else equal.

The proofs in this subsection rely on the convexity of the problem. Recall that the issue of convexity is complicated by the role of capital in the incentive compatibility constraints. We provide sufficient conditions on the utility function to ensure that a transformation of (20) is convex. Specifically,

Assumption 6. Let $U(x) \equiv \frac{u^{\prime \prime}(x)}{\left(u^{\prime}(x)\right)^{2}}$. $U(x)$ is non-decreasing in $x$.

The condition that $U(x)$ is non-decreasing is satisfied by power utility with a coefficient of relative risk aversion less than or equal to 1 . Note that this is a sufficient condition for convexity, and the results may still hold for more general utility functions.

In the Appendix, we prove the following proposition.

Proposition 6. Under Assumption $6 \tilde{k}$ is non-decreasing in $\mu$, and strictly increasing if $\tilde{k}<k^{*}$.

Proposition 6 states that an increase in expected endowment, all else being equal, leads to a higher level of capital. For intuition, consider the case when the endowment has two states, high and low. Let $c^{H}$ and $c^{L}$ denote consumption in the high and low state (next period), respectively, under the optimal allocation. Suppose that the optimum allocation, conditional on the current shock, implies a binding IC constraint next period in the high state, but not in the low state. At this optimum, it must be the case that any further increase in $\tilde{k}$ requires a decrease in $c^{L}$ in order to maintain the high state's IC constraint. (If not, then the government could increase consumption in all states by raising $\tilde{k}$, and so the original allocation could not have been an optimum.) The optimal $\tilde{k}$ is such that the loss from lowering $c^{L}$ exactly offsets the gain from increasing output through increased $\tilde{k}$. In this way, the government is forced to trade off higher income from additional capital against less insurance. Now, suppose that we provide the government with an additional unit of expected endowment. The marginal utility is highest in the low state and so the government will raise $c^{L}$. Recall that at the old $c^{L}$ it was indifferent to raising $\tilde{k}$ and lowering $c^{L}$. At the new, higher $c^{L}$ it will therefore strictly prefer to raise $\tilde{k}$. A similar intuition holds if it is the low state's IC that binds or if all constraints bind. 
We now consider a change to the probability measure $P$, holding constant the expected endowment $\mu$. Unlike the case with the scalar $\mu$, there are numerous dimensions along which we can perturb the probability measure. We consider a change in probability that lowers the probability on one state and increases the probability on all other states. In particular, we lower the probability on the state with the lowest consumption.

More formally, let $c\left(z^{\prime}\right)$ denote consumption in state $z^{\prime} \in Z$ under the optimal allocation associated with probability vector $P$. Define $z_{0}^{\prime}$ to be the state in which consumption is lowest. That is, $c\left(z_{0}^{\prime}\right) \leq c\left(z^{\prime}\right), \forall z^{\prime} \in Z$. If there is more than one state with the minimal consumption, without loss of generality we arbitrarily select one. Define a new probability measure $\hat{P}$ that satisfies the following: $\hat{P}\left(z_{0}^{\prime}\right)<P\left(z_{0}^{\prime}\right)$ and $\hat{P}\left(z^{\prime}\right)>P\left(z^{\prime}\right), \forall z^{\prime} \neq z_{0}^{\prime}$. We consider only $\hat{P}$ such that the constraint set is non-empty at $(\hat{P}, \mu)$. Let $\tilde{k}(\hat{P})$ and $\tilde{k}(P)$ denote the optimal capital stocks under $\hat{P}$ and $P$, respectively. In the appendix, we prove the following:

Proposition 7. Under Assumption $6, \tilde{k}(\hat{P}) \leq \tilde{k}(P)$, with a strict inequality absent perfect intra-period insurance (that is, if $\exists z^{\prime} \in Z$ such that $c\left(z^{\prime}\right)>c\left(z_{0}^{\prime}\right)$ ).

The intuition, like that of the "income" effect, stems from trading off an increase in capital against a decrease in consumption in states for which the IC constraints are slack. Raising the probability of the high-consumption states raises the cost of satisfying the IC constraints.

The algebra of the two-state case clarifies this point. Suppose that $c^{L}<c^{H}$ and the IC constraint is slack for $c^{L}$. Consider the optimal allocation under the original probability measure. The objective is equivalent to maximizing $p\left(z^{H}\right) u\left(c^{H}\right)+p\left(z^{L}\right) u\left(c^{L}\right)$, and the budget constraint implies

$$
c^{L}=\frac{F(\tilde{k})-r \tilde{k}+\mu-p\left(z^{H}\right) c^{H}}{p\left(z^{L}\right)} .
$$

The budget constraint highlights that an increase in $p\left(z^{H}\right) / p\left(z^{L}\right)$ raises the cost of consumption in the high state in terms of forgone consumption in the low state. However, this must be balanced by the fact that the high state has a larger weight in expected utility.

To sign these competing effects, consider a marginal increase in $\tilde{k}$. To satisfy the IC constraint, this requires an increase in $c^{H}$, which we denote $\frac{d c^{H}}{d \tilde{k}}$. The change in the objective function is therefore

$$
p\left(z^{H}\right) u^{\prime}\left(c^{H}\right) \frac{d c^{H}}{d \tilde{k}}+p\left(z^{L}\right) u^{\prime}\left(c^{L}\right)\left(\frac{F_{k}-r-p\left(z^{H}\right) \frac{d c^{H}}{d \tilde{k}}}{p\left(z^{L}\right)}\right) .
$$


Equating this to zero and rearranging implies at the optimum:

$$
F_{k}-r-p\left(z^{H}\right)\left(1-\frac{u^{\prime}\left(c^{H}\right)}{u^{\prime}\left(c^{L}\right)}\right) \frac{d c^{H}}{d \tilde{k}}=0 .
$$

Now at the optimal $\tilde{k}^{*}$, consider an increase in the probability of the high state to $\hat{p}\left(z^{H}\right)>$ $p\left(z^{H}\right)$. We now show that the marginal value of increasing $\tilde{k}$ (equation 21 ) becomes negative at $\tilde{k}^{*}$. Note that $\hat{p}\left(z^{H}\right)>p\left(z^{H}\right)$ directly reduces the left-hand side of (21). Any reduction in $c^{H}$ would violate the (originally binding) IC constraint in the high state, given that $\tilde{k}$ remains at $\tilde{k}^{*}$. Holding $\tilde{k}$ constant at $\tilde{k}^{*}$, the budget constraint requires that any increase in $c^{L}$ be accompanied by a decrease in $c^{H}$, which is not incentive compatible. Therefore, at $\tilde{k}^{*}$ and $\hat{p}\left(z^{H}\right)$, the marginal return to increasing $\tilde{k}$ is negative. Therefore, the optimal capital under $\hat{P}$ will be lower than under $P$.

Note that Proposition 7 concerns a shift of probability from low-consumption states to high-consumption states. Whether this corresponds to shifting probability from lowendowment states to high-endowment states depends on the parameters of the problem. In the numerical simulations discussed in the next subsection, it is always the case that (next period's) consumption is lowest when the (next period's) endowment shock is lowest.

To move from the relaxed problem to our original problem, we set $p\left(z^{\prime}\right)=q\left(z^{\prime} \mid z\right)$ and $\mu=$ $\sum_{z^{\prime}} q\left(z^{\prime} \mid z\right) z^{\prime}$. Now a change in the current state $z$ today has two effects. With persistence, an increase in $z$ increases $\mu$. All else equal, this leads to a higher capital stock. However, an increase in $z$ also reallocates probability mass from low-endowment states to high-endowment states. As shown by Proposition 7, this change in probabilities may reduce capital if it raises the likelihood of high consumption states.

Note that the substitution effect is zero under full insurance. Thus, if the Ramsey allocation is sustainable under $z$, there is no negative substitution effect on capital as we move from $z$ to $\hat{z}>z$. This leaves only the positive income effect. This is why we can unambiguously sign the impact on capital of an increase in $z$ at the Ramsey allocation. As we move away from the Ramsey allocation, whether the income effect or substitution effect dominates depends on the parameters of the problem. In the next subsection, we explore such cases numerically.

\subsection{A Numerical Example}

In this subsection we explore a numerical example that illustrates the previous analytical results and explores cases in which capital is higher following a low shock. We should note 
that this exercise is designed to shed light on the analytical results and is not meant to be a formal calibration.

To solve the problem numerically, we exploit the monotone nature of the Bellman operator and iterate the value function starting from the Ramsey allocation, which is an upper bound to the no-commitment value function. We consider two discrete values for $z: z_{H}=1$ and $z_{L}=$ 0.8. Utility is logarithmic in consumption, and production is Cobb-Douglas (specifically, $\left.F(k, l)=0.1 k^{0.33} l^{0.67}\right)$. The probability of $z^{\prime}=z_{H}$ conditional on $z=z_{H}$ is set to 0.89 . The probability of $z^{\prime}=z_{L}$ conditional on $z=z_{L}$ is also set to 0.89 , making the transition matrix symmetric.

We solve for the optimal allocation under a range of discount parameters, $\beta$. For each $\beta$, we obtain the optimal capital stocks, $k_{H}$ and $k_{L}$, following low- and high-endowment shocks, respectively. We plot the two series against the corresponding $\beta$ in Figure 1, Panel A. Panel B plots the ratio of $k_{H}$ to $k_{L}$. Note that for a given $\beta$, the comparison of $k_{H}$ to $k_{L}$ corresponds to comparing capital following a high- versus a low-endowment state along a particular equilibrium path.

As can be seen in Region I of each figure, $k_{H}=k_{L}=k_{W}$ when the agents are extremely impatient. That is, the myopia of the domestic agents makes the Markov equilibrium the only sustainable equilibrium.

As domestic agents become more patient, we enter Region II, in which the $k_{H}>k_{L}$. In this region, moving from $z_{L}$ to $z_{H}$ raises the expected endowment sufficiently that investment is greater following a high endowment. That is, the income effect of Proposition 6 dominates the substitution effect of Proposition 7.

Under the parameterization of the numerical example, there is a range of $\beta_{\mathrm{s}}$ in which the substitution effect dominates. This is Region III. In this region, $k_{H}<k_{L}$. Recall that in this situation, an increase in $q\left(z^{H}\right) / q\left(z^{L}\right)$ sufficiently raises the price of sustaining capital in terms of forgone consumption in the low state that the government opts to reduce capital. We should note that the existence of such a region is not guaranteed - there are other parameterized examples in which $k_{H} \geq k_{L}$ for all $\beta \in(0,1)$.

As $\beta$ increases, the government is able to achieve better insurance and still satisfy incentive compatibility. Better insurance makes the value of expected consumption less sensitive to relative probabilities. That is, insurance reduces the impact of raising $q\left(z^{H}\right) / q\left(z^{L}\right)$ on the expected consumption term in the budget constraint. (Recall from Proposition 7 that the substitution effect is zero under perfect insurance.) As the substitution effect diminishes, the income effect dominates again. That is, $k^{H}>k^{L}$ (Region IV). 
In Region $\mathrm{V}, k_{H}=k^{*}>k_{L}$. This region corresponds to Proposition 4 and the range $\left(\beta_{0}, \beta^{*}\right)$ in Proposition 5. Specifically, the first-best capital stock (and the Ramsey consumption allocation) is incentive compatible following a high shock, but not a low shock.

Finally, in Region VI, capital is always at the first-best level and the Ramsey allocation is implementable following all endowment shocks. This corresponds to the folk theorem (Proposition 3), which states that if agents are sufficiently patient, the Ramsey allocation is sustainable.

\section{Enriching the Asset Markets}

The main result of the previous sections concerns how the combination of incomplete markets and lack of commitment may lead to fiscal policies that prolong and deepen an economy's response to a shock. The analysis assumed an extreme form of incompleteness by ruling out all financial transactions. In this section, we discuss two extensions that enrich the menu of available assets.

The first extension adds financial contracts that allow the government to insure across shocks within a period, but not move resources across periods. Importantly, we assume that the credibility issues inherent in taxation also apply to the government's financial contracts. Subject to a feasibility condition on taxes, we show that this environment is isomorphic to the one described in the previous section.

The second extension adds a bond that allows the government to smooth consumption intertemporally. If the domestic agents discount the future at the rate of interest, consumption under the Ramsey allocation is a constant. That is, the Ramsey allocation replicates complete markets. This breaks the link between the history of shocks and the credibility of the Ramsey allocation. We conclude the section with some remarks regarding the intermediate case between our benchmark model and the complete markets case.

\subsection{Static Insurance Markets}

In this subsection, we extend the model to include "static" insurance contracts. That is, at node $z^{t-1}$, the government can buy and sell state-contingent assets that pay out $a\left(z^{t}\right)$ at history $z^{t}$. However, the government's portfolio is subject to the constraint $E\left(a\left(z^{t}\right) \mid z^{t-1}\right)=0$. The constraint implies that under risk-neutral pricing, the net value of the government's portfolio at the start of a period is always zero. The inability to carry net positions across 
periods is why the insurance contracts are considered "static."

The budget constraint is now given by

$$
c\left(z^{t}\right)=z_{t}+F\left(k\left(z^{t-1}\right), l\right)-\left(1-\tau\left(z^{t}\right)\right) F_{k}+a\left(z^{t}\right) .
$$

If the government deviates, it also loses its insurance claims:

$$
\bar{c}\left(z_{t}, k\right)=z_{t}+F(k, l)-(1-\bar{\tau}) F_{k} k .
$$

We now state the following equivalence result:

Proposition 8. For any equilibrium with $\left\{\tau\left(z^{t}\right), a\left(z^{t}\right)\right\}$, there exists a set of taxes $\tilde{\tau}\left(z^{t}\right)$ that, if less than or equal to $\bar{\tau}$, supports an equilibrium that uses no insurance $\left(\tilde{a}\left(z^{t}\right)=0\right)$ and delivers the same utility at any history.

Proof. Define $\tilde{\tau}\left(z^{t}\right)$ at $k=k\left(z^{t-1}\right)$ by equating net transfers to workers:

$$
\tau\left(z^{t}\right) F_{k}(k, l) k+a\left(z^{t}\right)=\tilde{\tau}\left(z^{t}\right) F_{k} k .
$$

This implies

$$
\tilde{\tau}\left(z^{t}\right)=\tau\left(z^{t}\right)-\frac{a\left(z^{t}\right)}{F_{k} k} .
$$

By construction, the budget constraint (22) implies that the consumption allocation under $\left(\tau\left(z^{t}\right), a\left(z^{t}\right)\right)$ is equivalent to that under $\left(\tilde{\tau}\left(z^{t}\right), 0\right)$ for any $k$. Since $E\left(a\left(z^{t}\right) \mid z^{t-1}\right)=0$, we have $E\left(\tilde{\tau}\left(z^{t}\right)\right)=E\left(\tau\left(z^{t}\right)\right)$ and therefore the capital stock is the same under both allocations. The deviation consumption $\bar{c}\left(z_{t}, k\right)$ is unchanged. As long as $\tilde{\tau}\left(z^{t}\right)$ satisfies the feasibility constraint $\tilde{\tau} \leq \bar{\tau}$ at each history, the sequence of $\tilde{\tau}\left(z^{t}\right)$ is an equilibrium delivering the original allocation.

The equivalence rests on the fact that taxation replicates intraperiod insurance due to the ex post inelasticity of capital. Therefore, transfers across states achieved via taxation have the same efficiency implications as those achieved using financial contracts. Moreover, the incentive to deviate depends only on net transfers from workers, regardless of whether they take the form of taxes/subsidies to capital or insurance payments. The latter statement, of course, requires the condition that the government face the same inability to commit to financial promises as it does in promises regarding fiscal policy. This implies that the incentive compatibility of an allocation does not depend on whether it is achieved through insurance contracts or taxation. 
Remark. While taxation of capital substitutes for intraperiod insurance, the assumptions of the benchmark model rule out the use of taxes to replicate more complicated assets. The (implicit) assumption of anonymity of capital rules out taxing individual capitalists at different rates. In particular, the government cannot promise capitalists that current actions will be compensated by payments beyond the next period. This rules out using taxation to replicate long-term financial contracts. Moreover, the timing of the budget constraint implies that period t's transfers must come from current income and not out of new investment that period. That is, the government cannot use current investment to pay transfers and then compensate investors from future endowments. Nor can it use the current endowment to subsidize investment for the next period, thereby indirectly investing in capital. This segmentation of each period's budget constraint rules out using taxation to replicate bonds.

\subsection{Debt}

The reason the credibility of the Ramsey allocation varies with the shock in our benchmark model is that consumption under the Ramsey allocation fluctuates as well. This feature is preserved under static insurance markets due to the restriction on intertemporal contracts. In this subsection, we introduce a one-period bond. Given the equivalence between taxation and intraperiod insurance demonstrated in the previous subsection, this is sufficient (subject to feasibility of taxes) to replicate the complete markets allocation under full commitment.

More formally, the value function of the government under full commitment solves the following Bellman equation:

$$
V(z, b)=\max _{k, c\left(z^{\prime}\right), b^{\prime}\left(z^{\prime}\right)} E\left[u\left(c\left(z^{\prime}\right)\right)+\beta V\left(z^{\prime}, b^{\prime}\left(z^{\prime}\right)\right) \mid z\right]
$$

subject to

$$
E\left[c\left(z^{\prime}\right) \mid z\right]+r^{*} k+E\left[b^{\prime}\left(z^{\prime}\right) \mid z\right] \leq E\left[z^{\prime} \mid z\right]+F(k, l)+\left(1+r^{*}\right) b
$$

where $b$ is the level of assets at the start of the period. Define $\gamma$ to be the Lagrange multiplier on (24). The first-order conditions are

$$
\begin{aligned}
u^{\prime}\left(c\left(z^{\prime}\right)\right) & =\gamma, \forall z^{\prime} \in Z \\
\beta V_{b^{\prime}}\left(z^{\prime}, b^{\prime}\left(z^{\prime}\right)\right) & =\gamma, \forall z^{\prime} \in Z \\
F_{k} & =r^{*}
\end{aligned}
$$

Equation (27) implies the familiar result that capital is always first best under the Ram- 
sey allocation. The envelope condition, $V_{b}(z, b)=\left(1+r^{*}\right) \gamma$, together with the first-order conditions, yields the usual Euler equation:

$$
u^{\prime}(c(z, b))=\beta\left(1+r^{*}\right) E\left[u^{\prime}\left(c\left(z^{\prime}, b^{\prime}\left(z^{\prime}\right)\right) \mid z\right] .\right.
$$

From (25), we have that consumption is equalized across states. The Euler equation then implies that along any history

$$
u^{\prime}\left(c\left(z^{t}\right)\right)=\beta\left(1+r^{*}\right) u^{\prime}\left(c\left(z^{t+1}\right)\right) .
$$

If we assume $\beta\left(1+r^{*}\right)=1$, from (28) and (29) we have that consumption is equalized across time and across states.

The Ramsey allocation therefore replicates the complete markets allocation. To maintain a constant level of consumption, the government uses a combination of taxes and debt. In response to a low shock, the government taxes capital and transfers part of the receipts to workers. If shocks are persistent, a shock today that is lower than the previous period's shock reduces expectations of future endowments. To smooth consumption going forward, the government saves part of the tax receipts. That is, the receipts from capital taxation in a low state insure against the innovation to the entire present discounted value of expected endowment that results from a low-endowment shock. The government's wealth leaving the period then exactly offsets the lower expected endowment stream.

Conversely, if today's shock is high relative to the previous period's shock, the government borrows/dis-saves (the change in the present discounted value of expected endowment) and subsidizes capital. The government then leaves the period with less wealth but a higher expected endowment stream. The combination of taxes and subsidies leaves ex ante capital taxes at zero and investment at its first-best level. We saw in Section 2 that taxes alone were not sufficient to smooth consumption when shocks were persistent. This was due to the fact the government had no vehicle to save tax receipts.

Note that, perhaps counterintuitively, the government borrows as the endowment increases and saves as the endowment falls. This is because taxation is used to insure the entire discounted value of the shocks. Persistence implies that the taxes/subsidies dominate the current endowment realization. The feature that the government borrows in high states and saves in low states is consistent with the evidence of countercyclical budget balances observed in the data for developing-country governments.

Note, as well, we have assumed that the complete markets allocation can be achieved 
through a combination of debt and taxes that does not violate the upper bound on tax rates $\tau$. This assumption is less innocuous than in the benchmark model. If shocks are sufficiently persistent, this assumption is likely not warranted given the fact that tax revenues are being used to insure against the entire discounted value of a shock.

We now ask whether the Ramsey allocation is incentive compatible absent commitment. We assume that, following a deviation, the government loses its assets and does not repay its debts. The continuation value after a deviation is then identical to the benchmark model's $W(z)$. The incentive constraints are now

$$
u\left(c\left(z^{\prime}\right)+\beta V\left(z^{\prime}, b^{\prime}\left(z^{\prime}\right)\right) \geq u\left(\bar{c}\left(k, z^{\prime}\right)\right)+\beta W\left(z^{\prime}\right), \forall z^{\prime} \in Z .\right.
$$

Note that under the Ramsey plan and $\beta\left(1+r^{*}\right)=1$, consumption is a constant $c^{*}$. We can solve for the present discounted value of utility:

$$
u\left(c\left(z^{\prime}\right)\right)+\beta V\left(z^{\prime}, b^{\prime}\left(z^{\prime}\right)\right)=\frac{u\left(c^{*}\right)}{1-\beta} .
$$

Therefore, the value of the Ramsey allocation at any point in time is independent of the history of shocks. In particular, the gains from deviating at any state $z^{t}$ are independent of the previous shocks $z^{t-1}$.

The ability to completely smooth consumption breaks the link between the histories and the gains from deviations. Therefore, it remains the case that if the Ramsey allocation is achievable at $z$, it is achievable at any $\hat{z}>z$, as claimed in Proposition 4 . However, the reverse is true as well: If the Ramsey allocation is achievable at $z$, it is achievable at any $\hat{z}<z$ as well. Put another way, if the Ramsey allocation is not incentive compatible for one $z \in Z$, it never satisfies incentive compatibility.

Remark. Note that this analysis of the incentive compatibility of the Ramsey allocation assumes $\beta\left(1+r^{*}\right)=1$. In this case, there are stochastic processes for endowment under which the Ramsey plan is sustainable. However, when $\beta\left(1+r^{*}\right)<1$, the Ramsey plan would require a forever-falling consumption profile, which cannot be incentive compatible. A reasonable conjecture is that such "impatience" drives the government to an incentivecompatible borrowing limit and that consumption eventually fluctuates in response to endowment realizations. The intuition of our benchmark model would then remain relevant, despite the potential for the government to borrow and lend. 


\section{Conclusion}

In this paper, we have explored the question of optimal fiscal policy in an open economy when the government lacks commitment and markets are incomplete. To provide a clear exposition of the mechanism underlying amplification, we considered a parsimonious specification in our benchmark model. The workers in this model are subject to endowment shocks that they cannot insure against. The government, which cares only about the workers (or a preferred subset of domestic agents), provides insurance through the use of linear taxes on capital. The insurance motive generates countercyclical taxes, but does not distort investment, under commitment.

It is when the government lacks commitment that fiscal policy becomes distortionary in our environment. We show that the incentive to deviate from the Ramsey allocation is greatest following low shocks. This reduces the government's credibility following a recession and depresses investment. In other words, the inability to commit, combined with the desire to provide insurance, generates a fiscal policy that prolongs and deepens recessions.

A key to the mechanism is that consumption is not perfectly smoothed intertemporally. We explored in detail the case of no dynamic financial contracts. At the other extreme, if the government can replicate the complete markets allocation, we show that the incentive to deviate is no longer history dependent. However, a reasonable conjecture is that if the government cannot smooth consumption perfectly over time, the amplification mechanism remains at work. We leave a formal exploration of this "intermediate" case to future research.

Our model is based on two key features that we think are important in characterizing emerging markets: imperfect access to financial markets and imperfect commitment. The latter may reflect the fact that emerging-market governments (or their respective constituencies) have relatively high discount rates. The paper demonstrates that in this environment, even a completely benevolent government would pursue policies that amplify and prolong shocks to output. 


\section{Appendix}

\section{A: Productivity Shocks}

In this appendix, we consider the case when $z$ is a productivity shock. Specifically, the production function takes the form

$$
y=z F(k, l)
$$

where $F$ is constant returns to scale in $k$ and $l$. Profit maximization by firms and capitalists' investment decisions imply the following two conditions:

$$
\begin{gathered}
z_{t} F_{l}\left(k\left(z^{t-1}\right), l\right)=w\left(z^{t}\right), \\
r^{*}=E\left[\left(1-\tau\left(z^{t}\right)\right) z_{t} \mid z^{t-1}\right] F_{k}\left(k\left(z^{t-1}\right), l\right) .
\end{gathered}
$$

The main deviation from the benchmark setup is that with persistent shocks, the optimal level of capital will vary with the state $z^{t-1}$. However, all the results of Section 2.3, with the exception of Proposition 4, extend to the multiplicative case with small alterations to the proofs. For instance, as in Proposition 1, when the government has full commitment, workers are completely insured intraperiod. Further ex ante taxes, $E\left(z_{t} \tau\left(z^{t}\right)\right)$, on capital equal 0 , and capital is at its first-best level. Proposition 4 does not extend immediately because $k^{*}\left(z_{t-1}\right)$ is increasing in $z_{t-1}$ under persistence.

Consumption under full commitment can be written as:

$$
c^{R}\left(z_{t} \mid z_{t-1}\right)=E\left(z_{t} \mid z_{t-1}\right) F\left(k^{*}\left(z_{t-1}\right), l\right)-r^{*} k^{*}\left(z_{t-1}\right),
$$

where $k^{*}(z)$ satisfies equation (32). As stated before, consumption at time $t$ under commitment is independent of the realization of the productivity shock at time $t, z_{t}$. Autarkic consumption similarly can be written as

$$
\bar{c}\left(z_{t}, k^{*}\left(z_{t-1}\right)\right)=z_{t}\left(F\left(k^{*}\left(z_{t-1}\right), l\right)-(1-\bar{\tau}) F_{k}\left(k^{*}\left(z_{t-1}\right), l\right)\right) k^{*}\left(z_{t-1}\right) .
$$

Since persistence implies that $E\left(z_{t} \mid z_{t-1}\right)$ is increasing in $z_{t-1}$, the first-best capital stock is larger following a high shock. Moreover, as $\bar{c}\left(z_{t}, k^{*}\left(z_{t-1}\right)\right)$ is increasing in $k^{*}$, a larger capital stock, all else equal, raises the gains to deviation.

The extension of Proposition 4 to this environment can be stated as follows: 
Proposition 9. Suppose that the multiplicative shock process is persistent and has full support. In a best sustainable equilibrium, if $k(z)=k^{*}(z)$ for some $z \in Z$, then $k\left(z^{\prime}\right)=k^{*}\left(z^{\prime}\right)$ for all $z^{\prime}>z$ if either of the following statements holds:

(i) The utility function is of the form $u(c)=\frac{c^{1-\theta}}{1-\theta}$ with $\theta \geq 1$ and the production function's "capital share, $\frac{F_{k} k}{F}$, is non-increasing in $k$; or

(ii) The production function is Cobb Douglas, $F(k, l)=k^{\alpha} l^{1-\alpha}$, and the shocks are such that $\bar{z} \leq \frac{(1-\alpha)}{\alpha} E(\hat{z} \mid z)$.

Proof. As in the proof of the Proposition 4 , we proceed by showing that, for any $z_{t}=\hat{z}$ such that the IC constraint binds following $z_{t-1}=z, u\left(c^{R}(\hat{z} \mid z)\right)-u\left(\bar{c}\left(\hat{z}, k^{*}(z)\right)\right)$ is increasing in $z$. Defining $\Delta(z, \hat{z}) \equiv u\left(\bar{c}\left(\hat{z}, k^{*}(z)\right)-u\left(c^{R}(\hat{z} \mid z)\right)\right.$, an equivalent statement is that $\Delta_{z}(z, \hat{z}) \leq 0$ if the IC constraint binds at $\hat{z}$ following $z$. The fact that $V(\hat{z}) \geq W(\hat{z}), \forall \hat{z} \in Z$, implies that $\Delta(z, \hat{z}) \geq 0$ when the IC constraint binds at $\hat{z}$. The expressions for $c^{R}$ and $\bar{c}$ are given by equations (33) and (34), respectively, with $z_{t}=\hat{z}$ and $z_{t-1}=z$. Substituting, we have

$$
\Delta=u\left[z_{t}\left(F-F_{k} k+\bar{\tau} F_{k} k\right)\right]-u\left[E\left(z_{t} \mid z_{t-1}\right)\left(F-F_{k} k\right)\right]
$$

where $k$ is shorthand for $k^{*}(z)$ and $F$ for $F\left(k^{*}\right)$.

Case (i): Under case (i), $u(c)=\frac{c^{1-\theta}}{1-\theta}, \theta \geq 0$ and $\frac{F_{k} k}{F}$ is non-increasing in $k$. Substituting and factoring out $F-F_{k} k$ gives

$$
\Delta=\left(F-F_{k} k\right)^{1-\theta}\left(u(\hat{z})\left(\frac{F-(1-\bar{\tau}) F_{k} k}{F-F_{k} k}\right)^{1-\theta}-u(E(\hat{z} \mid z))\right) .
$$

As $k=k^{*}(z)$ is increasing in $z$, the first term on the right is weakly decreasing in $z$, given that $\theta \geq 1$. Given that the the second term is non-negative when the IC constraint binds, the net effect of the first term is to reduce $\Delta$ as $z$ increases. The term $u(E(\hat{z} \mid z)$ is increasing in $z$, given persistence. The fact that this term is preceded by a minus sign also implies that this reduces $\Delta$ in response to an increase in $z$. It is therefore sufficient to show that $\left(\frac{F-(1-\bar{\tau}) F_{k} k}{F-F_{k} k}\right)^{1-\theta}$ is non-increasing in $z$. Or equivalently, given that $\theta \geq 1$ and that $k$ is increasing in $z$, we need to show that $\frac{F-(1-\bar{\tau}) F_{k} k}{F-F_{k} k}$ is non-decreasing in $k$. Differentiating and with some algebra, this is equivalent to showing that $1-\frac{F_{k} k}{F} \geq-\frac{F_{k k} k}{F_{k}}$. However, this is equivalent to the statement that $\frac{F_{k} k}{F}$ is non-increasing in $k$, which is the additional premise of case (i).

Case (ii): Under case (ii), the production function is Cobb-Douglas and the shocks satisfy 
$\frac{\bar{z}}{E\left(z_{t} \mid z_{t-1}\right)} \leq \frac{(1-\alpha)}{\alpha}$. The Cobb-Douglas assumption implies that at $k=k^{*}(z)$,

$$
E(\hat{z} \mid z) F_{k} k=E(\hat{z} \mid z) \alpha F=r^{*} k
$$

Using this, we can rewrite the Ramsey consumption allocation as $c^{R}(\hat{z} \mid z)=\left(\frac{1-\alpha}{\alpha}\right) r^{*} k$. Similarly, we have $\bar{c}(\hat{z}, k)=\hat{z}\left(F-(1-\bar{\tau}) F_{k} k\right)=\hat{z}(1-\alpha(1-\bar{\tau})) F$. Substituting, we have

$$
\Delta(z, \hat{z})=u(\hat{z}(1-\alpha(1-\bar{\tau})) F)-u\left(\left(\frac{1-\alpha}{\alpha}\right) r^{*} k\right) \equiv H(k)
$$

Given that $k$ is increasing in $z$, we need to show that $H(k)$ is non-increasing in $k$. Differentiating, we have

$$
H_{k}=u^{\prime}(\bar{c}) \hat{z}(1-\alpha(1-\bar{\tau})) F_{k}-u^{\prime}\left(c^{R}\right) \frac{1-\alpha}{\alpha} r^{*}
$$

At a binding IC constraint, $c^{R} \leq \bar{c}$. This implies, with some rearranging, that a sufficient condition for $H_{k} \leq 0$ is:

$$
\hat{z}(1-\alpha(1-\bar{\tau})) F_{k} \leq \frac{1-\alpha}{\alpha} r^{*} .
$$

Using the fact that $r^{*}=E(\hat{z} \mid z) F_{k}$, we need

$$
\hat{z}(1-\alpha(1-\bar{\tau})) \leq \frac{1-\alpha}{\alpha} E(\hat{z} \mid z)
$$

Given that $\hat{z}(1-\alpha(1-\bar{\tau})) \leq \bar{z}$, a sufficient condition for this to hold is

$$
\bar{z} \leq \frac{1-\alpha}{\alpha} E(\hat{z} \mid z)
$$

This is satisfied by the premise of case (ii). Note that persistence implies that if (36) holds for $z_{t-1}=z$, it holds for any $z_{t-1}>z$ as well.

Proposition 9 provides sufficient conditions for our main result that distortions, if they occur, always occur in low-productivity states. These conditions are satisfied under many standard assumptions. For example, case (i) is satisfied by a Cobb-Douglas production function and CRRA utility with a coefficient of relative risk-aversion greater than or equal to one.

The conditions of case (ii) rule out the possibility that capital responds "too much" to current productivity. Recall that the multiplicative case is complicated by the fact that the first-best capital stock is not constant, but generates an incentive to deviate in periods following a positive shock that may offset the increase in equilibrium consumption. The Cobb-Douglas production function with enough curvature (that is, $\alpha$ small), implies that 
first-best capital is sufficiently insensitive to shocks that the movement in capital does not dominate the response of the Ramsey consumption level in determining whether the IC constraints bind.

\section{B: Proof of Lemma 3}

We repeat Lemma 3:

Lemma 3 (Continuity). For all $z \in Z$, the value function, $V(z \mid \beta)$, is continuous at $\beta^{*}$.

Before the proof, we note that we cannot appeal directly to the Theorem of the Maximum because it is not necessarily the case that the constraint correspondence is continuous in $\beta$.

Proof. The Folk theorem states that the Ramsey allocation is sustainable for $\beta \geq \beta^{*}$. Recall that the Ramsey allocation is invariant to $\beta$ and the payoffs depend on $\beta$ only through the direct discounting. This implies that $V(z \mid \beta)$ is right continuous at $\beta^{*}$.

To prove left continuity at $\beta^{*}$, we first define the following quantities:

$$
\begin{aligned}
\hat{c}(z, k) & \equiv E\left(z^{\prime} \mid z\right)+F(k)-r k \\
\hat{V}(z, k \mid \beta) & \equiv \sum_{t=0}^{\infty} \sum_{z^{t}} \beta^{t} q\left(z^{t} \mid z\right) u\left(\hat{c}\left(z^{t}, k\right)\right) \\
\hat{H}\left(z^{\prime}, z, k \mid \beta\right) & \equiv u\left(\hat{c}\left(z^{\prime}, k\right)\right)+\beta \hat{V}\left(z^{\prime}, k, \beta\right)-u\left(\bar{c}\left(z^{\prime}, k\right)\right)-\beta W\left(z^{\prime} \mid \beta\right) .
\end{aligned}
$$

That is, $\hat{c}(z, k)$ is the consumption allocation that satisfies the budget constraint (8) when consumption is constant across states next period and capital is $k . \hat{V}(z, k \mid \beta)$ is the expected payoff from consuming $\hat{c}$ every period, holding constant $k$. Finally, $\hat{H}\left(z^{\prime}, z, k \mid \beta\right)$ is nonnegative when the consumption plan $\hat{c}(z, k)$, together with the constant capital stock $k$, satisfies the participation constraint at $z^{\prime}$ following $z$. Several remarks follow directly from these definitions:

(a) For all $z \in Z, \hat{V}(z, k \mid \beta)$ is continuous in $\beta$ and $k$;

(b) $\hat{V}\left(z, k^{*}, \beta^{*}\right)=V\left(z \mid \beta^{*}\right), \forall z \in Z$, as $k^{*}$ is optimal and sustainable at $\beta^{*}$;

(c) $\hat{H}\left(z^{\prime}, z, k^{*} \mid \beta^{*}\right) \geq 0, \forall\left(z^{\prime}, z\right) \in Z \times Z$, or the Ramsey allocation is sustainable at $\beta^{*}$.

We will use the fact that

$$
\hat{H}_{k}\left(z^{\prime}, z, k^{*} \mid \beta\right)<0, \forall\left(z^{\prime}, z\right) \in Z \times Z
$$


where $\hat{H}_{k}=\frac{\partial \hat{H}}{\partial k}$. This follows from (a) $k^{*}$ maximizes $\hat{c}(z, k)$ and $\hat{V}\left(z^{\prime}, k, \beta\right)$, and (b) $\bar{c}_{k}>0$. Equation (37) implies that small reductions in $k$ from $k^{*}$ strictly relax the participation constraints (which may already be slack). This, plus the fact that $\hat{V}$ is continuous in $k$ and both $\hat{V}$ and $W$ are continuous in $\beta$, implies that there exist $k_{0}<k^{*}$ and $\beta_{0}<\beta^{*}$ such that the participation constraints hold in the set $N_{0} \equiv\left(k_{0}, k^{*}\right] \times\left(\beta_{0}, \beta^{*}\right]$,

$$
\hat{H}\left(z^{\prime}, z, k, \beta\right) \geq 0, \forall(k, \beta) \in N_{0}
$$

By definition, continuity of $\hat{V}(z, k \mid \beta)$ in $k$ and $\beta$ imply that for each $\varepsilon>0$, there exists a neighborhood $N_{1}^{\varepsilon}$ of $\left(k^{*}, \beta^{*}\right)$, such that:

$$
\left|\hat{V}(z, k \mid \beta)-\hat{V}\left(z, k^{*} \mid \beta^{*}\right)\right|<\varepsilon, \forall z \in Z \text { and } \forall(k, \beta) \in N_{1}^{\varepsilon}
$$

Define $N_{\varepsilon}=N_{0} \bigcap N_{1}^{\varepsilon}$. This set is non-empty. Moreover, by construction of $N_{0}$, the incentive constraints are satisfied at allocations associated with elements of $N_{\varepsilon}$. That is, $\hat{V}\left(z^{\prime}, z, k \mid \beta\right) \leq$ $V(z \mid \beta) \leq V\left(z \mid \beta^{*}\right), \forall(k, \beta) \in N_{\varepsilon}$, where the second inequality follows from the fact that $V(z \mid \beta)$ is increasing in $\beta$. Moreover, by definition of $N_{1}^{\varepsilon},\left|\hat{V}(z, k \mid \beta)-V\left(z \mid \beta^{*}\right)\right|<\varepsilon$. Taken together:

$$
\left|V(z \mid \beta)-V\left(z \mid \beta^{*}\right)\right|<\varepsilon, \forall z \in Z \text { and } \forall(k, \beta) \in N_{\varepsilon} .
$$

This implies that $V(z \mid \beta)$ is also left continuous at $\beta^{*}$.

\section{C: Proofs of Propositions 6 and 7}

The proofs of Propositions 6 and 7 exploit the convexity of the government's problem. Recall that the issue of convexity is complicated by the role of capital in the incentive compatibility constraints. Assumption 6 is a sufficient condition on the utility function to ensure that a transformation of (20) is convex. Specifically, let $H \equiv F(k)$. Note that the inverses of $F$ and $u$ are well defined given strict monotonicity. Problem (20) is equivalent to the transformed problem:

$$
\tilde{V}(P, \mu ; V)=\max _{H, c\left(z^{\prime}\right)} \sum_{z^{\prime}} p\left(z^{\prime}\right)\left\{u\left(c\left(z^{\prime}\right)\right)+\beta V\left(z^{\prime}\right)\right\}
$$

subject to

$$
\begin{aligned}
\sum_{z^{\prime}} p\left(z^{\prime}\right) c\left(z^{\prime}\right)-H+r F^{-1}(H) & \leq \mu \\
H+z^{\prime}-u^{-1}\left(u\left(c\left(z^{\prime}\right)\right)+\beta\left(V\left(z^{\prime}\right)-W\left(z^{\prime}\right)\right)\right) & \leq 0, \forall z^{\prime} \in Z .
\end{aligned}
$$


Note that we have used the fact that $\bar{c}\left(k, z^{\prime}\right)=H+z^{\prime}$. For a given $P$, there is a non-empty range of $\mu$ for which the constraint set is non-empty. We have the following lemma:

Lemma 4. Under Assumption 6, problem (38) is convex.

Proof. The objective function is concave. The concavity of $F$ implies that $F^{-1}(H)$ is a convex function of $H$, implying that the budget set is convex. The IC constraints are linear in $H$. We therefore need to show that $u^{-1}\left(u\left(c\left(z^{\prime}\right)\right)+\beta\left(V\left(z^{\prime}\right)-W\left(z^{\prime}\right)\right)\right)$ is concave in $c\left(z^{\prime}\right)$ for all $z^{\prime} \in Z$. Define

$$
G(x) \equiv u^{-1}(u(x)+b)
$$

where $b \geq 0$. Differentiating:

$$
G^{\prime}(x)=\frac{u^{\prime}(x)}{u^{\prime}(G(x))}
$$

Differentiating again:

$$
\begin{aligned}
G^{\prime \prime}(x) & =\frac{u^{\prime \prime}(x)}{u^{\prime}(G(x))}-\frac{\left(u^{\prime}(x)\right)^{2} u^{\prime \prime}(G(x))}{\left(u^{\prime}(G(x))\right)^{3}} \\
& =\frac{\left(u^{\prime}(x)\right)^{2}}{u^{\prime}(G(x))}\left(\frac{u^{\prime \prime}(x)}{\left(u^{\prime}(x)\right)^{2}}-\frac{u^{\prime \prime}(G(x))}{\left(u^{\prime}(G(x))\right)^{2}}\right) .
\end{aligned}
$$

Therefore, $G^{\prime \prime} \leq 0$ if $\frac{u^{\prime \prime}(x)}{\left(u^{\prime}(x)\right)^{2}} \leq \frac{u^{\prime \prime}(G(x))}{\left(u^{\prime}(G(x))\right)^{2}}$. As $b \geq 0, G(x) \geq x$. Therefore, $G^{\prime \prime}(x) \leq 0$ if $\frac{u^{\prime \prime}(x)}{\left(u^{\prime}(x)\right)^{2}}$ is non-decreasing in $x$, which is Assumption 6. As this holds for arbitrary $b \geq 0$, it holds when we set $b=\beta\left(V\left(z^{\prime}\right)-W\left(z^{\prime}\right)\right) \geq 0$ for each $z^{\prime} \in Z$.

Let $\lambda\left(z^{\prime}\right)$ denote the multiplier on the IC constraint for $z^{\prime} \in Z$, and $\gamma$ the multiplier on the budget constraint. The Lagrangian for Problem (38) is:

$$
\begin{aligned}
\mathcal{L} & =\sum_{z^{\prime}} p\left(z^{\prime}\right)\left\{u\left(c\left(z^{\prime}\right)\right)+\beta V\left(z^{\prime}\right)\right\} \\
& -\gamma\left(\sum_{z^{\prime}} p\left(z^{\prime}\right) c\left(z^{\prime}\right)-H+r F^{-1}(H)-\mu\right) \\
& -\sum_{z^{\prime}} p\left(z^{\prime}\right) \lambda\left(z^{\prime}\right)\left(H+z^{\prime}-u^{-1}\left(u\left(c\left(z^{\prime}\right)\right)+\beta\left(V\left(z^{\prime}\right)-W\left(z^{\prime}\right)\right)\right) .\right.
\end{aligned}
$$

Note that the IC constraints have been multiplied through by $p\left(z^{\prime}\right)>0$. The first-order conditions are

$$
u^{\prime}\left(c\left(z^{\prime}\right)\right)-\gamma+\lambda\left(z^{\prime}\right) \frac{u^{\prime}\left(c\left(z^{\prime}\right)\right)}{u^{\prime}\left(u^{-1}\left(u\left(c\left(z^{\prime}\right)\right)+\beta\left(V\left(z^{\prime}\right)-W\left(z^{\prime}\right)\right)\right)\right)}=0
$$


and

$$
\gamma\left(1-\frac{r}{F^{\prime}\left(F^{-1}(H)\right)}\right)-\sum_{z^{\prime}} p\left(z^{\prime}\right) \lambda\left(z^{\prime}\right)=0
$$

We will use the following two lemmas:

Lemma 5. The value function $\tilde{V}(P, \mu ; V)$ is strictly concave in $\mu$.

Proof. In an optimal solution to problem (38), the budget constraint always binds. Let $x=(H, c()$.$) denote the choice vector of the problem, and denote by x(\mu)$ the optimum, given a value for $\mu$ (for the proof, we suppress the dependence on $P$ and $V$ ). Note that by the binding budget constraint we know that $x(\mu) \neq x\left(\mu^{\prime}\right)$. Let $\Omega(x)$ be the set of choices that are incentive compatible, which, as shown previously, is convex. Define $\Gamma(x) \equiv$ $\sum_{z^{\prime}} p\left(z^{\prime}\right) c\left(z^{\prime}\right)-H+r F^{-1}(H)$. Note that $\Gamma$ is strictly convex in $H$. Let $f(x)$ be the objective function of problem (38). Note that $f(x)$ is strictly concave in $c($.$) . We have that \tilde{V}(\mu)=$ $\sup \{f(x): x \in \Omega, \Gamma(x) \leq \mu\}$. For any $\mu_{1} \neq \mu_{2}$, it is the case that $x\left(\mu_{1}\right) \neq x\left(\mu_{2}\right)$, given that the budget constraint binds at an optimum.

If $c\left(\mu_{1}\right) \neq c\left(\mu_{2}\right)$, strict concavity of the objective function in $c($.$) implies that f\left(a x\left(\mu_{1}\right)+\right.$ $\left.(1-a) x\left(\mu_{2}\right)\right)>a f\left(x\left(\mu_{1}\right)\right)+(1-a) f\left(x\left(\mu_{2}\right)\right)$. By the convexity of the constraint sets and the fact that $\Gamma\left(x\left(\mu_{1}\right)\right) \leq \mu_{1}$ and $\Gamma\left(x\left(\mu_{2}\right)\right) \leq \mu_{2}$, we have that $x \in \Omega$ and $\Gamma(x) \leq a \Gamma\left(x\left(\mu_{1}\right)\right)+$ $(1-a) \Gamma\left(x\left(\mu_{2}\right)\right) \leq a \mu_{1}+(1-a) \mu_{2}$ for $x=a x\left(\mu_{1}\right)+(1-a) x\left(\mu_{2}\right)$. So, $\tilde{V}\left(a \mu_{1}+(1-a) \mu_{2}\right) \geq$ $f(x)>a f\left(x\left(\mu_{1}\right)\right)+(1-a) f\left(x\left(\mu_{2}\right)\right)=a \tilde{V}\left(\mu_{1}\right)+(1-a) \tilde{V}\left(\mu_{2}\right)$.

If $c\left(\mu_{1}\right)=c\left(\mu_{2}\right)$, then the binding budget constraint implies that $H\left(\mu_{1}\right) \neq H\left(\mu_{2}\right)$. Let $x=a x\left(\mu_{1}\right)+(1-a) x\left(\mu_{2}\right)$. Convexity implies that $x \in \Omega$, and strict convexity of $\Gamma$ implies that $\Gamma(x)<a \Gamma\left(x\left(\mu_{1}\right)\right)+(1-a) \Gamma\left(x\left(\mu_{2}\right)\right)$. Given that the budget constraint is slack at $x$, there exists $\hat{x} \in \Omega$ such that $\Gamma(\hat{x}) \leq a \mu_{1}+(1-a) \mu_{2}$ and for which the consumption allocations are strictly higher than in $x$. This implies that $f(\hat{x})>f(x)$. Therefore, $\tilde{V}\left(a \mu_{1}+(1-a) \mu_{2}\right) \geq$ $f(\hat{x})>f(x)=a \tilde{V}\left(\mu_{1}\right)+(1-a) \tilde{V}\left(\mu_{2}\right)$.

Taken together, we have that

$$
\tilde{V}\left(a \mu_{1}+(1-a) \mu_{2}\right)>a \tilde{V}\left(\mu_{1}\right)+(1-a) \tilde{V}\left(\mu_{2}\right)
$$

for $\mu_{1} \neq \mu_{2}$ and $a \in(0,1)$.

Lemma 6. Let $\hat{\gamma}$ and $\gamma$ be the multipliers associated with (39) when the expected endowment is $\hat{\mu}$ and $\mu$, respectively. If $\hat{\mu}>\mu$, then $\hat{\gamma}<\gamma$. 
Proof. The envelope theorem implies that $\gamma=\frac{\partial \tilde{V}}{\partial \mu}$. The result follows, as $\tilde{V}$ is strictly concave in $\mu$.

We are now ready to prove Proposition 6 , which we repeat here.

Proposition 6. Under Assumption 6, $\tilde{k}$ is non-decreasing in $\mu$ and strictly increasing if $\tilde{k}<k^{*}$.

Proof. We prove an equivalent statement in the transformed problem: $H$ is non-decreasing in $\mu$ and strictly increasing if $H<F\left(k^{*}\right)$.

Let $\left(c\left(z^{\prime}\right), H\right)$ be the optimal allocation under $\mu$, and $\left(\gamma, \lambda\left(z^{\prime}\right)\right)$ be the associated multipliers. Define $G\left(c\left(z^{\prime}\right), z^{\prime}\right) \equiv u^{-1}\left(u\left(c\left(z^{\prime}\right)\right)+\beta\left(V\left(z^{\prime}\right)-W\left(z^{\prime}\right)\right)\right)$. Define $Z_{\text {cons }} \equiv\left\{z^{\prime} \in Z\right.$ : $\left.\lambda\left(z^{\prime}\right)>0\right\}$ to be the set of states in which the IC constraint binds.

Define $\Lambda\left(c\left(z^{\prime}\right), \gamma, z^{\prime}\right)$ by

$$
\Lambda\left(c\left(z^{\prime}\right), \gamma, z^{\prime}\right) \equiv \frac{u^{\prime}\left(G\left(c\left(z^{\prime}\right), z^{\prime}\right)\right)}{u^{\prime}\left(c\left(z^{\prime}\right)\right)}\left(1-\frac{u^{\prime}\left(c\left(z^{\prime}\right)\right)}{\gamma}\right) .
$$

The first-order conditions (40) imply that $\Lambda=\frac{\lambda\left(z^{\prime}\right)}{\gamma}$. Note that $\Lambda$ is increasing in $\gamma$. Assumption 6 , together with $G\left(c\left(z^{\prime}\right), z^{\prime}\right) \geq c\left(z^{\prime}\right)$, implies that $\Lambda$ is increasing in $c\left(z^{\prime}\right)$.

Now consider an increase in the expected endowment to $\hat{\mu}>\mu$. Denote the new allocation and multipliers by "hatting" the respective variables. To create a contradiction, suppose that $\hat{H}<H$. That is, capital is lower under the new allocation. This implies that $F^{\prime}\left(F^{-1}(\hat{H})\right)>$ $F^{\prime}\left(F^{-1}(H)\right)$. From (41), this implies that

$$
\begin{aligned}
\left(1-\frac{r}{F^{\prime}\left(F^{-1}(\hat{H})\right)}\right)=\sum_{z^{\prime}} p\left(z^{\prime}\right) \frac{\hat{\lambda}\left(z^{\prime}\right)}{\hat{\gamma}} & >\sum_{z^{\prime}} p\left(z^{\prime}\right) \frac{\lambda\left(z^{\prime}\right)}{\gamma}=\left(1-\frac{r}{F^{\prime}\left(F^{-1}(H)\right)}\right) \\
\sum_{z^{\prime}} p\left(z^{\prime}\right) \Lambda\left(\hat{c}\left(z^{\prime}\right), \hat{\gamma}, z^{\prime}\right) & >\sum_{z^{\prime}} p\left(z^{\prime}\right) \Lambda\left(c\left(z^{\prime}\right), \gamma, z^{\prime}\right) .
\end{aligned}
$$

As $p\left(z^{\prime}\right)>0$, this requires that there exist at least one $z^{\prime}$ at which $\Lambda\left(\hat{c}\left(z^{\prime}\right), \hat{\gamma}, z^{\prime}\right)>$ $\Lambda\left(c\left(z^{\prime}\right), \gamma, z^{\prime}\right)$. Call this $z_{1}^{\prime}$. From lemma $6, \hat{\gamma}<\gamma$. As $\Lambda$ is increasing in $\gamma$ and $c$, this implies that $\hat{c}\left(z_{1}^{\prime}\right)>c\left(z_{1}^{\prime}\right)$. If $z_{1}^{\prime} \in Z_{\text {cons }}$, then $\hat{\lambda}\left(z_{1}^{\prime}\right)=0$. This follows from the fact that $\hat{c}\left(z_{1}^{\prime}\right)>c\left(z_{1}^{\prime}\right)$ and $\hat{H}<H$, which means that the IC constraint must be slack. Therefore, $0=\Lambda\left(\hat{c}\left(z_{1}^{\prime}\right), \hat{\gamma}, z_{1}^{\prime}\right)<\Lambda\left(c\left(z_{1}^{\prime}\right), \gamma, z_{1}^{\prime}\right)$, a contradiction of the definition of $z_{1}^{\prime}$. 
Now suppose $z_{1}^{\prime} \notin Z_{\text {cons }}$. Then the fact that $\hat{c}\left(z_{1}^{\prime}\right)>c\left(z_{1}^{\prime}\right)$ plus $\hat{H}<H$ again implies that $\hat{\lambda}\left(z_{1}^{\prime}\right)=0$. Therefore, $\Lambda\left(\hat{c}\left(z^{\prime}\right), \hat{\gamma}, z^{\prime}\right)=0=\Lambda\left(c\left(z^{\prime}\right), \gamma, z^{\prime}\right)$. In neither case does $\Lambda\left(\hat{c}\left(z_{1}^{\prime}\right), \hat{\gamma}, z_{1}^{\prime}\right)>\Lambda\left(c\left(z_{1}^{\prime}\right), \gamma, z_{1}^{\prime}\right)$. Therefore, no such $z_{1}^{\prime}$ exists and $\hat{H}<H$ cannot be an optimal allocation.

Suppose now $\hat{H}=H$ when $H$ is less than the first best. We will now derive a contradiction. If $\hat{H}=H$ is the optimal allocation, then $\hat{c}\left(z^{\prime}\right) \geq c\left(z^{\prime}\right), \forall z^{\prime} \in Z$. To see this, suppose that $\lambda\left(z^{\prime}\right)>0$. Then the claim must be true in order for the IC constraint to hold at $\hat{c}\left(z^{\prime}\right)$. If $\lambda\left(z^{\prime}\right)=0$, then $u^{\prime}\left(c\left(z^{\prime}\right)\right)=\gamma>\hat{\gamma} \geq u^{\prime}\left(\hat{c}\left(z^{\prime}\right)\right) \Rightarrow c\left(z^{\prime}\right)<\hat{c}\left(z^{\prime}\right)$.

Now for any $z^{\prime}$ such that $c\left(z^{\prime}\right)=\hat{c}\left(z^{\prime}\right)$, we have $\Lambda\left(\hat{c}\left(z^{\prime}\right), \hat{\gamma}, z^{\prime}\right)<\Lambda\left(c\left(z^{\prime}\right), \gamma, z^{\prime}\right)$ as $\hat{\gamma}<\gamma$. For any $z^{\prime}$ such that $\hat{c}\left(z^{\prime}\right)>c\left(z^{\prime}\right)$, we have $\hat{\lambda}\left(z^{\prime}\right)=0$, which implies $0=\Lambda\left(\hat{c}\left(z^{\prime}\right), \hat{\gamma}, z^{\prime}\right) \leq$ $\Lambda\left(c\left(z^{\prime}\right), \gamma, z^{\prime}\right)$. Taken together, this implies that $\Lambda\left(\hat{c}\left(z^{\prime}\right), \hat{\gamma}, z^{\prime}\right) \leq \Lambda\left(c\left(z^{\prime}\right), \gamma, z^{\prime}\right)$, with at least one strict inequality unless $\hat{\lambda}\left(z^{\prime}\right)=0, \forall z^{\prime} \in Z$ (that is, the Ramsey allocation). However, if $\hat{\lambda}\left(z^{\prime}\right)=0, \forall z^{\prime} \in Z$, then $\hat{H}$ is the first best. Then our premise $\hat{H}=H$ and $H$ is sub-optimal therefore implies that

$$
\sum_{z^{\prime}} p\left(z^{\prime}\right) \Lambda\left(\hat{c}\left(z^{\prime}\right), \hat{\gamma}, z^{\prime}\right)<\sum_{z^{\prime}} p\left(z^{\prime}\right) \Lambda\left(c\left(z^{\prime}\right), \gamma, z^{\prime}\right)
$$

Plugging this into first-order condition (41) and rearranging gives $F^{\prime}\left(F^{-1}(\hat{H})\right)<F^{\prime}\left(F^{-1}(H)\right)$, a contradiction of $\hat{H}=H$.

We now prove Proposition 7, which we repeat here:

Proposition 7. Under Assumption $6, \tilde{k}(\hat{P}) \leq \tilde{k}(P)$, with a strict inequality absent perfect intra-period insurance (that is, $\exists z^{\prime} \in Z$ such that $c\left(z^{\prime}\right)>c\left(z_{0}^{\prime}\right)$ ).

Proof. We prove an equivalent statement in the transformed problem: $H(\hat{P})=F(\tilde{k}(\hat{P})) \leq$ $H(P)=F(\tilde{k}(P))$, with a strict inequality absent perfect insurance.

Let $\left(c\left(z^{\prime}\right), H\right)$ be the optimal allocation under $(P, \mu)$ and $\left(\gamma, \lambda\left(z^{\prime}\right)\right)$ be the associated multipliers. Consider the alternative problem in which the probability measure is $\hat{P}$. Define a new expected endowment $\hat{\mu}$ such that $H(P)$ is optimal under $(\hat{P}, \hat{\mu})$. We first must establish that such a $\hat{\mu}$ exists. The Theorem of the Maximum implies that the optimal $H$ is an upper hemi-continuous function of $\mu$. ( See Stokey and Lucas 1989, Theorem 3.6. We omit the proof that our constraint correspondence is continuous and compact valued in $\mu$. We note, however, that the proof uses the fact that the constraint set in the transformed problem is convex.) By Proposition 6, the optimal $H$ is monotonic in $\mu$. Therefore, we can trace a continuous, monotonic mapping from $\mu$ to optimal $H$. The final complication is that for a 
given $P$, there exists a minimum expected endowment $\underline{\mu}(P)$ below which the constraint set is empty (although it may be the case that $\mu(P)$ is negative). The proof below concerns the case of $\hat{\mu} \geq \underline{\mu}(\hat{P})$. If $\hat{\mu}<\underline{\mu}(\hat{P})$, we can establish the result with a symmetric proof that begins with $\hat{\hat{P}}$ and considers a shift to $P$. We omit this latter case from this appendix, as the details follow closely the following proof.

We now characterize the relationship between $\hat{\mu}$ and $\mu$. If it is the case that $\hat{\mu}>\mu$, then by Proposition 6 , the optimal $H(\hat{P})$ under $(\hat{P}, \mu)$ is less than that under $(P, \mu)$.

Let $\left(\hat{c}\left(z^{\prime}\right), \hat{H}\right)$ be the optimal allocation under $(\hat{P}, \hat{\mu})$, and $\left(\hat{\gamma}, \hat{\lambda}\left(z^{\prime}\right)\right)$ be the associated multipliers. By construction, $\hat{H}=H(P)$.

Recall that by definition, $z_{0}^{\prime}$ is such that $c\left(z_{0}^{\prime}\right) \leq c\left(z^{\prime}\right), \forall z^{\prime} \in Z$. We have two cases to consider: (i) $\hat{c}\left(z_{0}^{\prime}\right) \geq c\left(z_{0}^{\prime}\right)$, and (ii) $\hat{c}\left(z_{0}^{\prime}\right)<c\left(z_{0}^{\prime}\right)$.

(i) Suppose that $\hat{c}\left(z_{0}^{\prime}\right) \geq c\left(z_{0}^{\prime}\right)$.

This implies that $\hat{c}\left(z^{\prime}\right) \geq c\left(z^{\prime}\right), \forall z^{\prime}$. To see this, note that if $c\left(z^{\prime}\right)>c\left(z_{0}^{\prime}\right)$, then $\lambda\left(z^{\prime}\right)>0$. As $H$ is held constant, the IC constraint under the new problem requires $\hat{c}\left(z^{\prime}\right) \geq c\left(z^{\prime}\right)$. On the other hand, if $c\left(z^{\prime}\right)=c\left(z_{0}^{\prime}\right)$ and if it were the case that $\hat{c}\left(z^{\prime}\right)<c\left(z^{\prime}\right)$, then given the premise of case (i) $\left(c\left(z_{0}^{\prime}\right) \leq \hat{c}\left(z_{0}^{\prime}\right)\right)$, we would have that $\hat{c}\left(z^{\prime}\right)<c\left(z^{\prime}\right)=c\left(z_{0}^{\prime}\right) \leq \hat{c}\left(z_{0}^{\prime}\right)$. This in turn implies $\hat{\lambda}\left(z_{0}^{\prime}\right)>0$. Given that $\hat{c}\left(z_{0}^{\prime}\right) \geq c\left(z_{0}^{\prime}\right)$, and the incentive constraint is binding for $\hat{c}\left(z_{0}^{\prime}\right)$, it is the case that $\lambda\left(z_{0}^{\prime}\right)>0$. The fact that $c\left(z_{0}^{\prime}\right) \leq c\left(z^{\prime}\right), \forall z^{\prime} \in Z$ then implies that $\lambda\left(z^{\prime}\right)>0, \forall z^{\prime} \in Z$. But if all incentive constraints are binding at the allocation $c($.) given $H$, then $\hat{c}\left(z^{\prime}\right)<c\left(z^{\prime}\right)$ is not incentive compatible at $H$. Therefore $\hat{c}\left(z^{\prime}\right) \geq c\left(z^{\prime}\right), \forall z^{\prime}$.

By construction, $\hat{P}$ places more probability on the states with relatively high consumption. Therefore, given that $\hat{c}\left(z^{\prime}\right) \geq c\left(z^{\prime}\right), \forall z^{\prime}$, it is the case that $\sum_{z^{\prime}} \hat{p}\left(z^{\prime}\right) \hat{c}\left(z^{\prime}\right) \geq$ $\sum_{z^{\prime}} p\left(z^{\prime}\right) c\left(z^{\prime}\right)$, with strict inequality in the absence of perfect insurance (that is, as long as there exists one $z^{\prime}$ such that $\left.c\left(z^{\prime}\right)>c\left(z_{0}^{\prime}\right)\right)$. The new optimal allocation consumes more resources for the same $H$, so the budget constraint requires that $\hat{\mu} \geq \mu$, with strict inequality absent perfect insurance.

(ii) Suppose that $\hat{c}\left(z_{0}^{\prime}\right)<c\left(z_{0}^{\prime}\right)$. Given that $H$ is the same, this implies that at the original allocation, the incentive constraint has to be slack at $z_{0}$. Therefore $\lambda\left(z_{0}^{\prime}\right)=0$ and $\gamma=u^{\prime}\left(c\left(z_{0}^{\prime}\right)\right)$. Note that it is always the case that $u^{\prime}\left(\hat{c}\left(z_{0}^{\prime}\right)\right) \leq \hat{\gamma}$. By the premise $\hat{c}\left(z_{0}^{\prime}\right)<c\left(z_{0}^{\prime}\right)$, it follows that $\hat{\gamma} \geq u^{\prime}\left(\hat{c}\left(z_{0}^{\prime}\right)\right)>u^{\prime}\left(c\left(z_{0}^{\prime}\right)\right)=\gamma$. Define $\Lambda\left(c\left(z^{\prime}\right), \gamma, z^{\prime}\right)$ as in (42). Recall that $\Lambda$ is increasing in its first two arguments, and $\Lambda\left(c\left(z^{\prime}\right), \gamma, z^{\prime}\right)=\frac{\lambda\left(z^{\prime}\right)}{\gamma}$. The first-order condition 
(41), plus the fact that $H(P)$ is optimal under both allocations, implies that

$$
\left(1-\frac{r}{F^{\prime}\left(F^{-1}(H)\right)}\right)=\sum_{z^{\prime}} \hat{p}\left(z^{\prime}\right) \Lambda\left(\hat{c}\left(z^{\prime}\right), \hat{\gamma}, z^{\prime}\right)=\sum_{z^{\prime}} p\left(z^{\prime}\right) \Lambda\left(c\left(z^{\prime}\right), \gamma, z^{\prime}\right)
$$

We now show that $\hat{c}\left(z_{0}^{\prime}\right)<c\left(z_{0}^{\prime}\right)$ contradicts $(44)$. For $z^{\prime}$ such that $\lambda\left(z^{\prime}\right)=0$, non-negativity of $\Lambda$ implies that $\Lambda\left(\hat{c}\left(z^{\prime}\right), \hat{\gamma}, z^{\prime}\right) \geq \Lambda\left(c\left(z^{\prime}\right), \gamma, z^{\prime}\right)=0$. Note that if $\lambda\left(z^{\prime}\right)=0, \forall z^{\prime} \in Z$, we have achieved the Ramsey allocation. As consumption is equalized across states, moving from $P$ to $\hat{P}$ does not change the cost of the consumption basket. Therefore, the Ramsey allocation is feasible under $\hat{P}$ at $H(P)$. Consequently, $\hat{c}\left(z_{0}^{\prime}\right)<c\left(z_{0}^{\prime}\right)$ can not be optimal. So, under the premise of case (ii), there exists a $z^{\prime}$ such that $\lambda\left(z^{\prime}\right)>0$. For the set of such $z^{\prime}$, the IC constraints require $\hat{c}\left(z^{\prime}\right) \geq c\left(z^{\prime}\right)$. As $\Lambda$ is increasing in its first two arguments, $\hat{\gamma}>\gamma$ and $\hat{c}\left(z^{\prime}\right) \geq c\left(z^{\prime}\right)$ imply that $\Lambda\left(\hat{c}\left(z^{\prime}\right), \hat{\gamma}, z^{\prime}\right)>\Lambda\left(c\left(z^{\prime}\right), \gamma, z^{\prime}\right)$. As $\hat{P}$ takes probability mass away from a state in which $\Lambda\left(\hat{c}\left(z^{\prime}\right), \hat{\gamma}, z^{\prime}\right) \geq \Lambda\left(c\left(z^{\prime}\right), \gamma, z^{\prime}\right)=0$ and puts additional mass on every other state, we have

$$
\sum_{z^{\prime}} \hat{p}\left(z^{\prime}\right) \Lambda\left(\hat{c}\left(z^{\prime}\right), \hat{\gamma}, z^{\prime}\right)>\sum_{z^{\prime}} p\left(z^{\prime}\right) \Lambda\left(c\left(z^{\prime}\right), \gamma, z^{\prime}\right)
$$

which contradicts (44). Therefore case (ii) never happens.

Given that the only case that satisfies the first-order conditions is case (i), it is the case that $\hat{\mu} \geq \mu$. From Proposition 6 , the optimal $H$ under $(\hat{P}, \mu)$ is less than or equal to that under $(P, \mu)$, with strict inequality absent perfect insurance. 


\section{References}

[1] Albuquerque, Rui and Hugo Hopenhayn (2004), "Optimal Lending Contracts and Firm Dynamics", Review of Economic Studies, Vol. 71, No. 2, pp 285-315

[2] Benhabib, Jess and Aldo Rustichini (1997), "Optimal Taxes without Commitment", Journal of Economic Theory, vol. 77,Issue 2, pp. 231-259.

[3] Benhabib, Jess and Andres Velasco (1996), "On the optimal and best sustainable taxes in an open economy", European Economic Review, vol 40, pp. 135-154.

[4] Calvo, Guillermo, Alejandro Izquierdo, and Ernesto Talvi (2005), "Phoenix Miracles: Recovering from systemic financial crises in emerging markets," working paper.

[5] Chamley, Christophe (1986), "Optimal Taxation of Capital Income in General Equilibrium with Infinite Lives", Econometrica, Vol. 54(3), pp. 607-622.

[6] Chari, V. V., Lawrence J. Christiano and Patrick Kehoe (1994), "Optimal Fiscal Policy in a Business Cycle Model", Journal of Political Economy, Vol. 102 (4), pp. 617-652.

[7] Chari, V. V. and Patrick Kehoe (1990), "Sustainable Plans", Journal of Political Economy, Vol. 98, pp. 783-802.

[8] Chari, V. V. and Patrick Kehoe (1999), "Optimal Fiscal and Monetary Policy", in John Taylor and Michael Woodford, ed., Handbook of Macroeconomics, vol $1 C$, Elsevier.

[9] Judd, Kenneth L. (1985), "Redistributive Taxation in a Simple Perfect Foresight Model", Journal of Public Economics, Vol 28, pp. 59-83.

[10] Kaminsky, Graciela, Carmen Reinhart, and Carlos Vegh (2004), "When it Rains, it Pours: Procyclical Capital Flows and Macroeconomic Policies", NBER Macroeconomics Annual. Edited by Mark Gertler and Kenneth Rogoff.

[11] Kehoe, Patrick and Fabrizio Perri (2002), "International Business Cycles with Endogenous Incomplete Markets", Econometrica, Vol 70(3), pp. 907-928.

[12] Krussel, Per and Jose-Victor Rios-Rull (1999), "On the Size of the U.S. Government: Political Economy in the Neoclassical Growth Model," American Economic Review, Vol. 89 (5) 1156-81. 
[13] Lane, Philip and Aaron Tornell (1999), "The Voracity Effect", American Economic Review, Vol 89(1), pp. 22-46

[14] Phelan, Christopher and Ennio Stacchetti (2001), "Sequential Equilibria in a Ramsey Tax Model", Econometrica, Vol 69 (6), pp. 1491-1518.

[15] Stokey, Nancy and Robert Lucas (1989), Recursive Methods in Economic Dynamics Cambridge: Harvard University Press

[16] Talvi, Ernesto and Carlos Vegh (2004), "Tax Base Variability and Procyclical Fiscal Policy" NBER WP 7499. Forthcoming in Journal of Development Economics.

[17] Thomas, Jonathan and Tim Worrall (1994), "Foreign Direct Investment and the Risk of Expropriation", Review of Economics Studies, Vol. 61, No.1, pp. 81-108.

[18] Tornell, Aaron and Andres Velasco (1992), "The Tragedy of the Commons", Journal of Political Economy, Vol. 100, No. 6, pp 1208-1231

[19] Zhu, Xiadong (1992), "Optimal Fiscal Policy in a Stochastic Growth Model", Journal of Economic Theory, Vol. 58, pp. 250-289. 
Figure 1

Panel A: Optimal Capital for Various Discount Rates

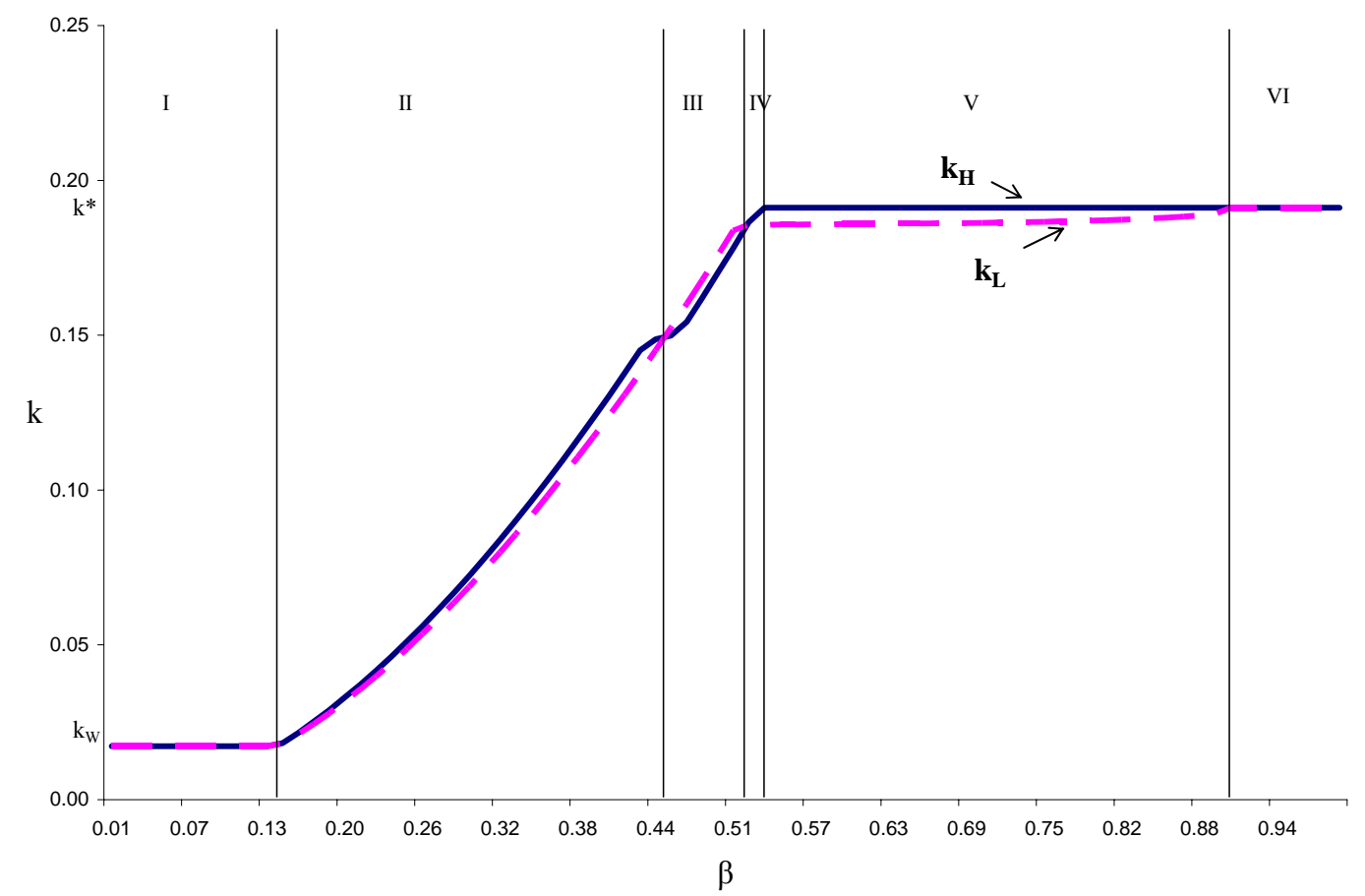

Panel B: The Ratio of Optimal Capital following High and Low Shocks

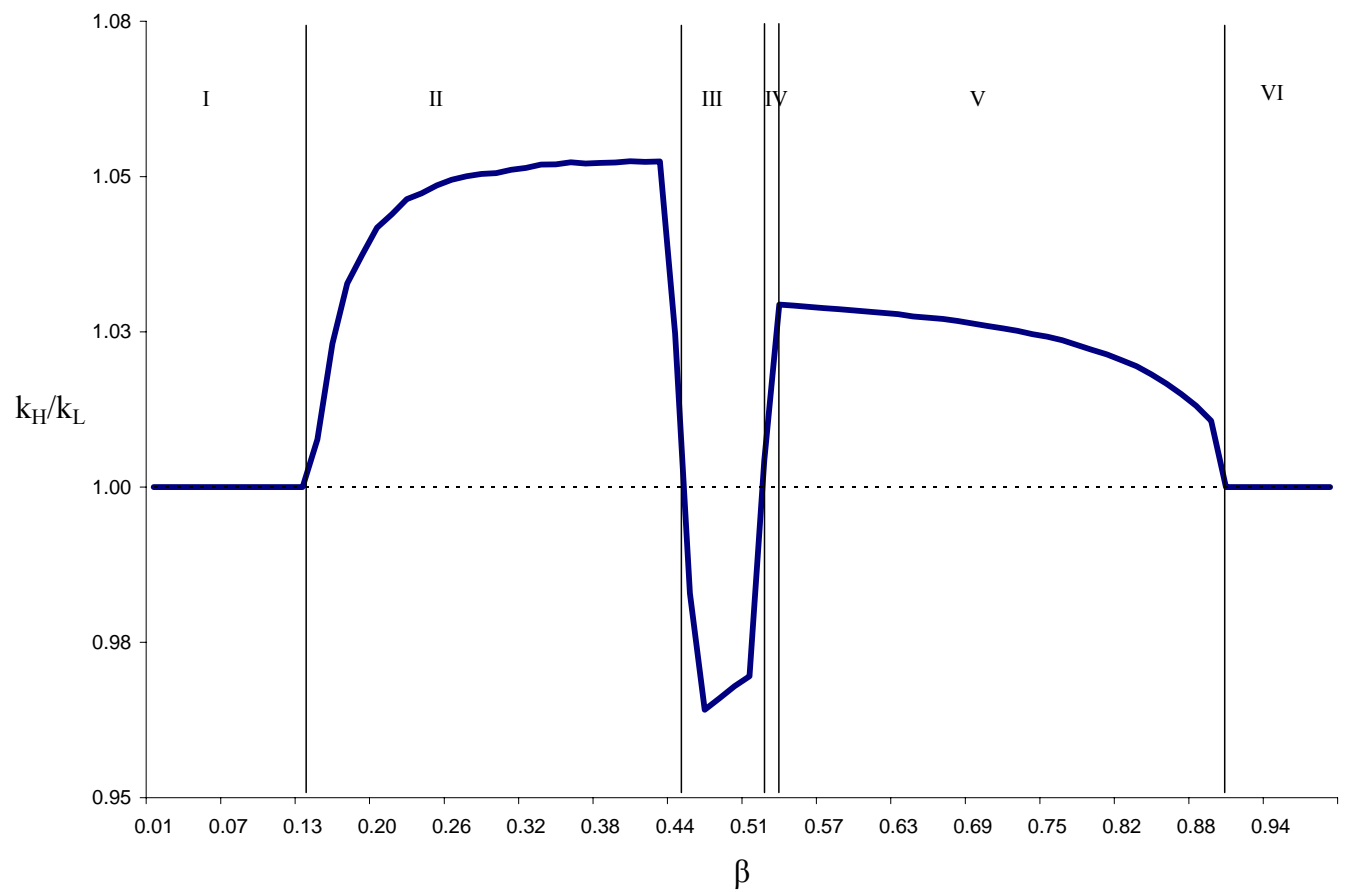

Note: $\mathrm{k}_{\mathrm{H}}$ and $\mathrm{k}_{\mathrm{L}}$ refer to the optimal capital stocks following a high- and low-endowment shock, respectively. Each point corresponds to the equilibrium capital stocks, given $\beta$. See text for details. 